\title{
Seismic Evaluation of Self-Centering Bi-Rocking Walls via Micro Modeling of Rocking Joints: Locating the Rocking Section
}

Vahid Broujerdian ( $\nabla$ broujerdian@iust.ac.ir) Iran University of Science and Technology https://orcid.org/0000-0003-3454-4797

Esmaeil Mohammadi Dehcheshmeh

Iran University of Science and Technology

\section{Research Article}

Keywords: self-centering, concrete shear wall, rocking wall, higher mode effects, residual deformation

Posted Date: August 31st, 2021

DOl: https://doi.org/10.21203/rs.3.rs-844271/v1

License: (c) (i) This work is licensed under a Creative Commons Attribution 4.0 International License.

Read Full License 


\title{
Seismic evaluation of self-centering bi-rocking walls via micro modeling of rocking joints: locating the rocking section
}

\author{
Vahid Broujerdian ${ }^{* a}$, Esmaeil Mohammadi Dehcheshmeh ${ }^{\text {b }}$ \\ ${ }^{a}$ Assistant Professor, School of Civil Engineering, Iran University of Science and Technology \\ broujerdian@iust.ac.ir \\ ${ }^{\text {b }}$ PhD Candidate School of Civil Engineering, Iran University of Science and Technology \\ esmaeil_mohammadi@civileng.iust.ac.ir
}

\begin{abstract}
The rocking concrete shear wall is one of the new self-centering seismic systems applied in high-rise buildings. To reduce the effects of higher modes on base-rocking walls, the idea of using multiple rocking walls has been evolved. This paper presents a comparative investigation on the seismic performance of base-rocking and bi-rocking wall systems. To this aim, structures of 4-, 8-, 12-, 16-, and 20- stories have been evaluated subjected to three sets of seismic earthquake records including 22 Far Field (FF), 14 Near Field (NF) with pulse, and 14 Near Field (NF) no-pulse ground motions. The nonlinear time-history analyses were conducted in two directions using OpenSEES software. To determine the appropriate location of rocking section in bi-rocking walls, one-quarter (R2-M1), one-half (R2-M2), and three-quarter (R2-M3) models were examined. The obtained results revealed that R2-M3 model is not efficient in reducing the effects of higher modes. However, R2-M2 model in high-rise buildings under FF and NF-nopulse records could be effective in decreasing the moment by a maximum of nearly $41 \%$ and the shears by a maximum of $25 \%$ and $18 \%$, respectively. Furthermore, the results showed that bi-rocking walls could not be effective in reducing the influence of higher modes under NF-pulse ground motions. Generally, the residual drifts were negligible in all the rocking systems under study.
\end{abstract}

Keywords: self-centering; concrete shear wall; rocking wall; higher mode effects; residual deformation

\section{Introduction}

Self-Centering (SC) systems are viable alternatives to conventional seismic resistant systems in order to decrease residual displacements and post-earthquake costs concentrating damages in fuse members. Possessing both the mechanisms of restoring force and energy dissipating (ED) SC systems have flag-shaped force-displacement curves under cyclic lateral loads, as shown in

\footnotetext{
${ }^{*}$ Corresponding author
} 
Figure 1. The restoring force mechanism restores the deformed structure into its original position under lateral loads (Masrom and Hamid 2020). A restoring force with a gap opening mechanism without ED presents a bilinear lateral load-displacement curve. To provide an ED mechanism in the system, energy absorption elements need to be installed. The ED diagram, as demonstrated in Figure 1, does not bring about SC behavior in the system. By combining these two mechanisms, the flag-shaped behavior is created (Figure 1).

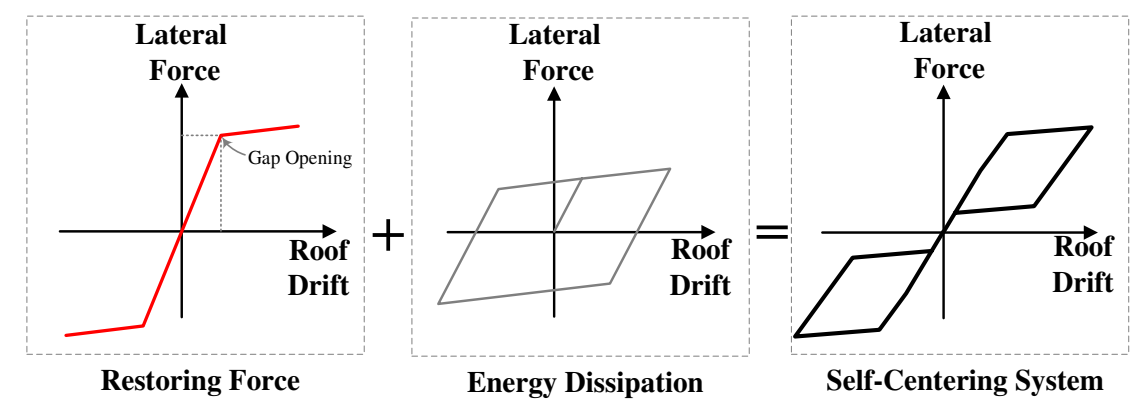

Figure 1. Behavior of SC systems

Rocking walls, as one of the common SC systems, composed of both restoring force and ED mechanisms. The restoring force mechanism in the system is provided by Post-Tensioning (PT) the cables between the wall and the foundation or the rocking blocks, and after the lateral force overcomes the restoring force, the gap opening in this system is always provided by rotating the wall relative to the foundation or the wall blocks relative to each other. ED fuses in rocking systems, including plain bar, butterfly-shaped fuse, and viscous damper, which are usually used in gap openings or around the wall in the rotation of the wall, can be employed in different rocking core positions (Chancellor et al. 2014).

\subsection{Literature review}

Various studies have been conducted on rocking wall systems, including design concepts (Perez, et al. 2004, Kurama 2001, and Pennucci, et al. 2009) experimental studies (Holden, Restrepo, and Mander 2003, Restrepo and Rahman 2007, and Perez, et al. 2013), and parametric studies (Perez 1998, Kurama et al. 1999, Kurama 2000, and Kurama 2002). In this section, a brief review of recent studies on the base-rocking and multiple rocking wall systems and the effects of higher modes is presented. 
The design method for rocking systems being proposed for fast and simple configuration of rocking systems has been developed using non-dimensional ED and PT tendons parameters (Mpampatsikos et al. 2020). Subsequent studies investigate five effective parameters in the cyclic analysis of SC concrete walls, namely wall aspect ratio, initial stress of post-tensioned (PT) tendons, total area of PT tendons, total area of mild steels, and yielding tensile strength of mild steels ( $\mathrm{Gu}$ et al. 2019). Owing to their results, to increase the efficiency of the system, the area of ED should be increased and the structural drift should be improved through increasing in the wall aspect ratio and initial stress of PT tendons.

In self-centering rocking wall systems, dissipating energy mechanisms include inherent viscous damping, pounding damping due to the wall rocking on the foundation, and other available hysteretic damping. Nazari and Sritharan (2020) concluded that the rocking walls absorb a low portion of seismic input energy. Although they have a small amount of inherent damping, they have an acceptable seismic performance, proposing their potential application in seismic resistant structures. However, Guo et al. (2020) examined two dampers including concentrated control device (CCD), and distributed control device (DCD) in rocking wall systems. It showed that DCD can sufficiently decrease the story drift response of rocking wall systems subjected to nearfield pulse-like ground motions but it causes a significant drift concentration. In contrast, CCD does not have a considerable effect on story drift response, yet sufficiently avoids drift concentration.

Wiebe (2013) showed that the effect of higher modes on structures with the rocking behavior is destructive. Disregarding higher mode effect in design increases the vulnerability of the structure. Moreover, the design of the structure may become non-economic if the structure is designed against these effects. Therefore, the effects of higher modes in structures must be reduced. Wiebe and Christopoulos (2015) showed that reducing the restraints at the base and creating rocking behavior on the foundation would increase the effects of higher modes and result in additional seismic demands. It concluded that most responses of mid-rise structures are controlled by modes 1 and 2, while in high-rise structures, higher modes would also affect the responses of the structure.

Direct displacement-based design (DDBD) method utilizes an equivalent SDOF model to estimate the seismic demands ignoring the higher mode effects. Rahgozar and Rahgozar (2020) 
has generalized the DDBD procedure for self-centering systems. In this method, modal responses are combined via the modified SRSS at the design displacement point. The conventional lateral load distributions, such as the inverted triangular and uniform pattern, cannot predict the design forces of self-centering rocking systems due to higher mode effects. To overcome this deficiency, the continuous cantilever beam analogy may be utilized to account for the highermode effects (Rahgozar and Rahgozar 2021).

The analysis of the shear force and moment distributions along the height of the tall rise structures revealed that rocking shear wall systems may be affected by the higher modes to a greater extent with respect to traditional RC structures. Higher moments and shear forces were shown at most levels of the rocking systems. Similarly, higher demand increases induced by earthquake inputs of greater intensity, were generally seen in the rocking structures (Aragaw and Calvi 2020).

Multiple-rocking system in Reference (Eatherton et al. 2014) was introduced schematically by placing several rocking blocks on top of each other and connecting those using PT tendons and ED elements. In Reference (Martin and Deierlein 2021), multiple-rocking systems have been called stacked rocking frame. Wiebe and Christopoulos (2009) and Khanmohammadi and Heydari (2015) suggested using multiple rocking shear wall system to reduce the higher-mode effects. In the case of rocking movement in high-rise structures, the shear force of stories and the moment caused by the effects of higher modes are increased. However, providing multiple rocking joints in different heights reduces the moment in the height of the structure. The residual deformation of the structure, therefore, would become zero or insignificant. Moreover, it has been shown that utilizing multiple rocking sections increases the demand for PT force in cables and reduces the demand for rotation in the wall. So the residual displacements and the impacts generated at contact surfaces become negligible. Using multiple rocking systems in height is not effective for low-rise buildings, e.g. less than eight stories. In high-rise buildings, as the number of rocking blocks in the wall increases, the efficiency of the wall also enhances. According to the previous studies (Wiebe and Christopoulos 2009, and Khanmohammadi and Heydari 2015) the drift profiles of base-rocking structures are completely different from those of multiple rocking structures. A research conducted on low-rise multiple rocking systems revealed that the use of unbonded bars with the partially reduced area as ED elements prevents the wall from cracking 
and crushing (Kang, et al. 2013). Furthermore, the research showed that this type of wall compared to the one with bonded rebars and also to the conventional reinforced concrete walls has more energy dissipating and deformation capacity and less degradation of stiffness and strength. Reference (Grigorian and Kamizi 2019) has likened multilevel rocking cores (MLRCs) to human spine under similar loading conditions. Then, reliable formulae for the preliminary design of simple MLRCs have provided.

In a study conducted on reinforced concrete high-rise buildings, a method called MechRV3D was proposed to diminish the effects of higher modes (Tong and Christopoulos 2020). To control the effects of higher modes in the MechRV3D method, the moment is monitored by applying the reversible rocking function of the gravity system and the shear is monitored by an independent system at the core base.

The rocking wall system can also be employed in conjunction with the moment frame system called RWMF system. RWMF combinations are special earthquake resistant structures that are capable of damage control, omission of residual effects, collapse prevention (CP), and postearthquake realignment and repairs (PERR) (Grigorian 2021). Shoujun et al. (2016) suggested that the effect of higher modes in base rocking systems is inevitable. Furthermore, estimation of the shear forces and the moment demands based on the first mode is non-conservative. It also reported that the maximum displacement in base-rocking system is not influenced by the higher modes. In fact, the base-rocking wall make the frames to vibrate in the first mode inducing large forces in the frames to eliminate the higher mode shapes. Wu, Zhao, and $\mathrm{Lu}$ (2018) investigated the effect of restraint percentage of rocking core base and the stiffness ratio of the rocking core to the moment frames on the dynamic behavior of the RWMF system. In that research, to simulate the moment frame and rocking core system, shear and moment beams were used, respectively. Then the closed-form solution has been compared to the results of finite element modeling. The aforementioned study tried to determine the range of base restraint and the stiffness ratio which lead to a uniform distribution of relative displacements which in turn reduce the higher mode effects.

Guo et al. (2020) simulated RWMF system in a simplified manner by equating the system with a flexural-shear beam. Then it solved the corresponding closed-form equation. In another study 
(Sun et al. 2018), designing moment frame systems via Pin-supported Wall-Frame (PWF) structures using a displacement-based seismic design approach has been investigated.

In recent years, the rocking wall systems have been used in practice. Figure 2 shows G3 Building on Suzukakedai campus of the Tokyo Institute of Technology in Japan. It is an 11-story steel-reinforced concrete (SRC) structure which is rehabilitated using rocking walls and metal dampers (Wada et al. 2011). In similar cases, Li et al. (2021) has retrofitted the low rise concrete frame systems by self-centering rocking wall structure in experimental work.

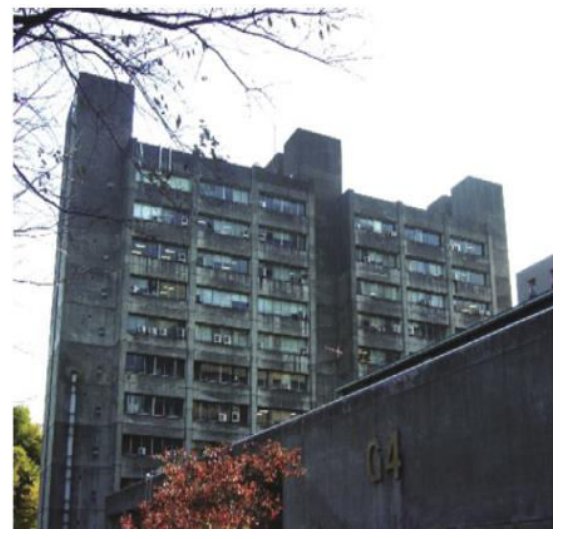

(a)

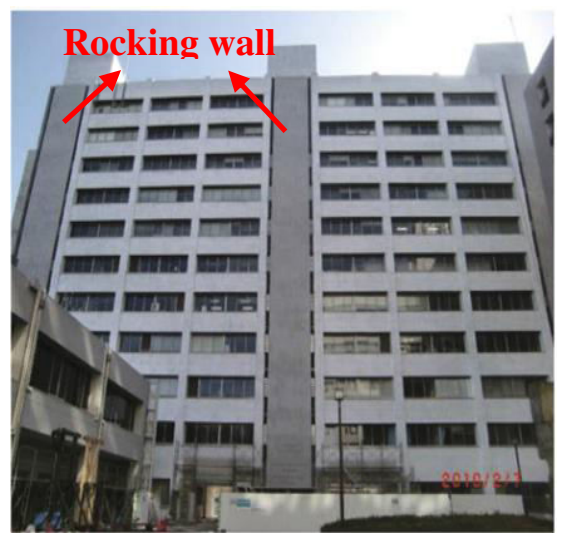

(b)

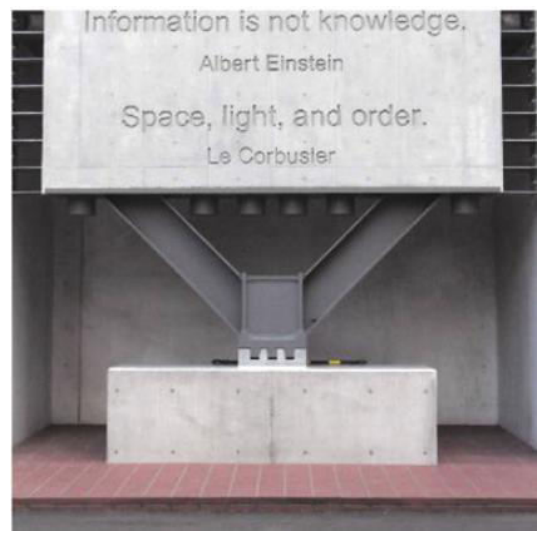

(c)

Figure 2. The north views of G3 Building before and after the rehabilitation (Wada et al. 2011): a) before rehabilitated; b) rehabilitated; c) pinned connection at the bottom of the rocking walls

The effects of higher modes which can bring about undesirable and inevitable effects have also been investigated in other rocking systems such as rocking bracing system (Hasan 2012). The main technique suggested to reduce the negative effects of higher modes is creating rocking blocks at height to reduce the moment in the core and using energy dissipater at the bottom of the core to reduce the shear force. Low-amplitude and large-amplitude shake table tests have corroborated the efficiency of this technique under seismic loading (Wiebe et al. 2013a 2013b). Previous studies assert that rocking sections in the lower half of the section are more effective than the upper half; and adding a third rocking block to a 30-story building is more effective than to a 20-story building. For design multiple-rocking bracing systems, the modified modal superposition (MMS) method has been developed (Martin and Deierlein 2021).

\subsection{Aims and scopes}


Based on the literature review on the effect of higher modes in rocking systems, some studies have simulated multiple rocking walls using multiple torsion springs (Wiebe and Christopoulos 2009 and $\mathrm{Li}$ et al. 2017). However, their seismic behavior under different seismic records have not been studied. Therefore, the present study is aimed at investigating the effects of NF (pulse and no pulse) and FF seismic records on the behavior of rocking walls. In this regard, to reduce the effects of higher modes, best location of the rocking section in bi-rocking walls is investigated. This study provides an appropriate and effective configuration of bi-rocking walls under different seismic records.

\section{Method of study}

\subsection{Restoring force factor of the SC system}

Figure 3 demonstrates the desired flag-shaped behavior of rocking wall systems. In this figure, $M_{\text {Decomp }}$ is the decompression moment of rocking section, $M_{y}$ is the moment corresponding to the yielding of the anchors, at which the ED elements are completely yielded, $M_{u}$ is the final moment of the system, $M_{E D y}$ is the moment of energy dissipation, and .

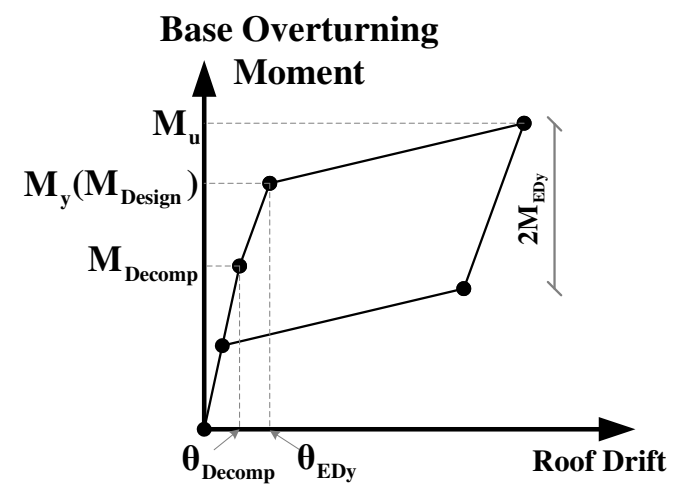

Figure 3. Flag-shaped behavior of rocking systems

Defining the restoring coefficient, $\lambda$, as:

$$
\lambda=\frac{M_{u}-M_{E D y}}{M_{E D y}}
$$

if $\lambda$ is equal to one, system restoring will be provided and the flag-shaped behavior would be achieved. By increasing the value of $\lambda$, the certainty of the system restoring becomes greater. Considering the uncertainties including the possibility of damages to concrete edges, yielding of cables in severe earthquakes, and possible increase of ED resistance, it is better to select greater 
values of $\lambda$ to ensure the restoring mechanism in the system. If $\lambda$ is less than one, no restoring mechanism takes place in the system and it experiences residual drifts under seismic loading. In the present study, according to Pennucci et al. (2009) research, the value of $\lambda$ is considered to be equal to 1.25 .

In equation (1), the parameters are calculated using the following equations,

$$
\begin{aligned}
& M_{u}=l_{p t t i} F_{i n, p t, i}+l_{p t, i} F_{s t, p t, i}+l_{p t, j} F_{i n, p t, j}+l_{p t, j} F_{s t, p t, j}+l_{e d, i} F_{y, e d, i}+l_{e d, j} F_{y, e d, j}+w l_{w} / 2 \\
& M_{E D y}=l_{e d, i} F_{y, e d, i}+l_{e d, j} F_{y, e d, j}
\end{aligned}
$$

The required parameters for the calculation of $M_{u}$ and $M_{E D y}$ are provided in Figure 4. Energy dissipators $\left(E D_{i}, E D_{j}\right)$ and PT tendons $\left(P T_{i}\right.$ and $\left.P T_{j}\right)$ were used on both sides of the section. $F_{i n, p t, i}$ and $F_{s, p t, i}$ are the PT force and extra force, respectively, developed in the tendon $i^{\text {th }}$ from decompression point to the energy dissipator yield point. These parameters for other tendons are designated by index j. $F_{s t, p t, i}$ and $F_{s t, p t, j}$ are the designed extra force developed in the $i^{t h}$ and $j^{t h}$ tendons after decompression up to the final point. $F_{y, e d, i}$ and $F_{y, e d, j}$ are the yield forces of $i^{\text {th }}$ and $j^{\text {th }}$ energy dissipator. The total length of the wall, the length of the energy dissipators, the distance of energy dissipators from the edge, and the distance of post-tensioned tendons from the edge are specified by $l_{w}, l_{u b s}, d_{e d}$, and $d_{p t}$, respectively, and selected according to Pennucci et al. (2009). The other different length $\left(l_{p t, i}, l_{p t, j}, l_{e d, i}\right.$, and $\left.l_{e d, j}\right)$ is shown in Figure 4. The w is the gravitational load weight on the wall. The constant $v$, which is used to determine the depth of the compression zone, can be in the range of 0.15 to 0.3 in these systems. In the current research, $v$ was considered equal to $0.17(v=0.17)$ according to Pennucci et al. (2009). 

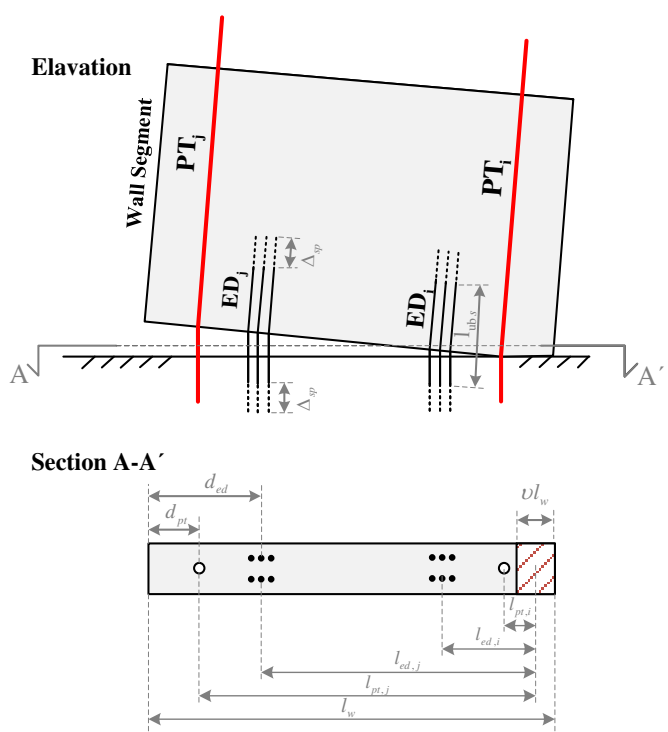

Figure 4. Rocking wall parameters at the connection with the foundation (Pennucci et al. 2009)

To design the self-centering rocking walls the decompression force $\left(F_{\text {Decomp }}\right)$, yield force $\left(F_{y}\right)$, and secondary stiffness $\left(k_{\text {rock }}\right)$ of the system are determined according to the following equations (Wiebe and Christopoulos 2009). Note that reducing the tendon stiffness does not affect the initial stiffness of the system.

$$
\begin{aligned}
& F_{\text {Decomp }}=\left(w+F_{P T}\right)\left(\frac{l_{w}}{2 H_{e f f}}\right) \\
& F_{y}=\left(\frac{w+F_{P T}}{1-\beta / 2}\right)\left(\frac{l_{w}}{2 H_{e f f}}\right) \\
& \beta=2\left(1-\frac{F_{\text {Decomp }}}{F_{y}}\right) \\
& k_{\text {rock }}=\left(\frac{A_{P T} E_{P T}}{L_{P T}}\right)\left(\frac{l_{w}}{2 H_{e f f}}\right)^{2}
\end{aligned}
$$

\subsection{The limit state of SC rocking wall systems}

The schematic view of the bi-rocking system considered in this study, is shown in Figure 5a. As shown in this figure, it has a rocking section at a desired height in addition to the base rocking joint. Figure 5b demonstrates the limit states of this system. The limit states of the bi-rocking wall, according to Figure 5b, has 6 limit points. However, the limit states of the base rocking wall include 5 limit points. At point 1, the system is free of lateral loads. Due to the posttensiond (PT) cables, the initial stiffness of the system corresponds to the stiffness of the wall. After the lateral load overcomes the PT force, uplifting in the system occurs at point 2. After 
point 2, the effective stiffness is due to the PT cables and the initial stiffness of the base ED elements. The effective stiffness remains constant up to point 3 where the base ED elements yields. After point 3, the stiffness of the system corresponds to the elastic stiffness of the cables and the secondary stiffness of the base ED elements. By increasing the lateral load, the next limit state of the bi-rocking system is point 5 corresponding to the yielding of ED elements at upper rocking section. However, in base-rocking system, the limit state of point 5' corresponds to yielding of the PT cables. It must be noted that allocating the rocking sections at higher stories results in approaching point 5 to point 5 '. After the limit state of cable yielding, the slope of the curve will become less than the previous region. The curve will continue to points 6 and 6 ' for birocking and base-rocking systems, respectively. Points 6 and 6' are related to the failure in the core or cable failure for both rocking and bi-rocking states. Rocking wall systems should be designed in a way that the core fails before the cable failure, since the damage to the cable would cause permanent deformations in the system and the structure would probably overturn. It is worth noting that because of the high failure strain of the mild steel, it is assumed that in the limit states of 6 and 6', the ED elements are not ruptured.

(a)

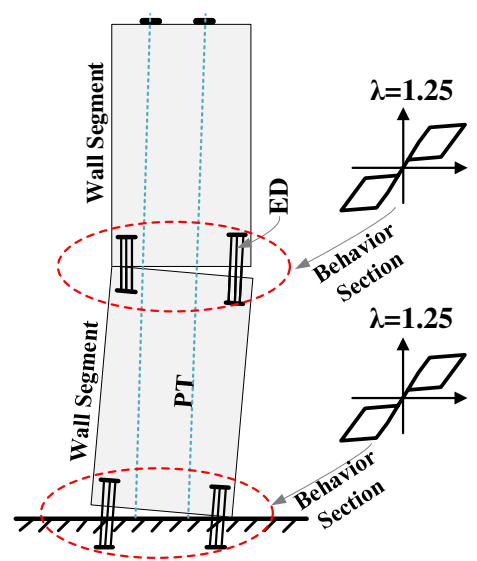

(b)

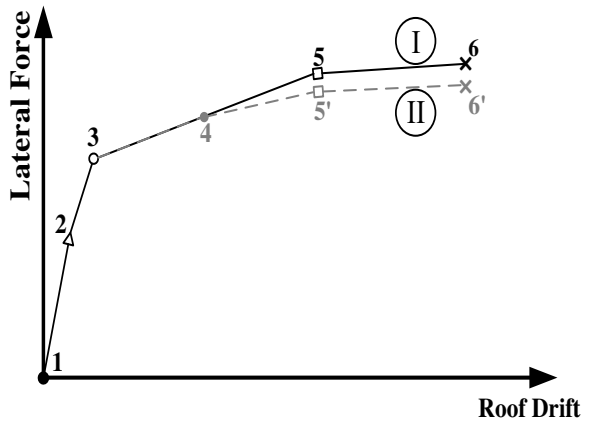

Figure 5. Limit states of base-rocking and bi-rocking systems

\subsection{Numerical modeling}

The schematic view of the numerical model of the considered bi-rocking wall is presented in Figure 6a. The simulation is made in OpenSEES software. Figure 6b shows the core modeling of the wall, which is considered to be elastic with the properties of the designed concrete section. According to the previous studies (Wiebe and Christopoulos 2009 and Khanmohammadi and Heydari 2015), in the design of wall elements, concrete is not allowed to be non-linear at the 
base of the wall. Thus, the assumption of linear deformation in concrete is a correct assumption in analysis. At the joints of the blocks, hard contact springs and EDs are employed. To simulate EDs, Steel02 material is used. The PT tendons were used for joint at the top of the walls to base. The PT tendons had the behavior of non-compressive materials and elastic perfectly-plastic gap (ElasticPPGap) uniaxial materials with initial prestressing. To simulate the $P-\Delta$ effect of the middle gravity frames and its effect on the lateral wall seismic system, a leaning column was used (Figure 6b). To model the leaning column and the end components of the walls, rigid elements are used (Figure 6).

(a)

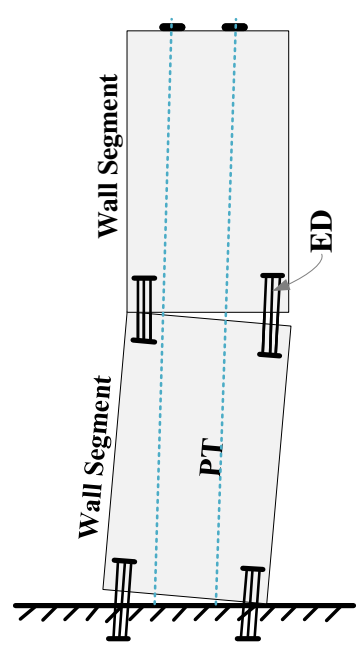

(b)

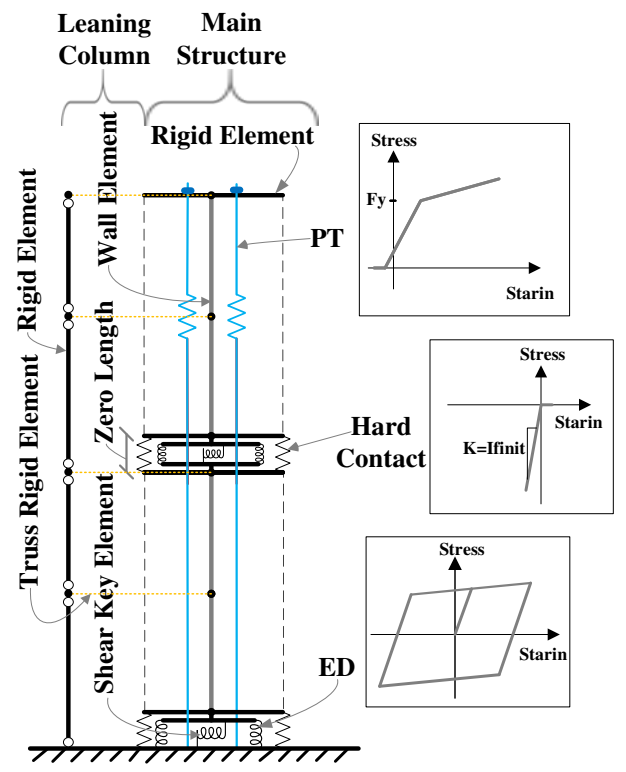

Figure 6. Numerical model of SC bi-rocking wall

\subsection{Specifications of the numerical models}

Twenty buildings including 4-, 8-, 12-, 16-, and 20- story structures are investigated in this research. The plan shown in Figure 7a with the dimensions of $25 \mathrm{~m} \times 40 \mathrm{~m}$ is considered for all of the models similar to the reference (Pennucci et al. 2009). Figure $\mathbf{7 b}$ illustrates different types of rocking walls considered as the lateral load bearing system for the examined buildings. As shown in this figure, four types of rocking wall are used including a base-rocking wall (R1) and three bi-rocking walls with the second rocking section at H/4 (R2-M1), H/2 (R2-M2), and 3H/4 (R2-M3) where $\mathrm{H}$ is the wall height. The effective seismic weights of all stories are considered to be equal to $2500 \mathrm{kN}$. The mechanical properties of concrete are $f^{\prime}{ }_{c}=40 \mathrm{MPa}$ and $E_{c}=$ $30 \mathrm{GPa}$, the properties of EDs are $f_{y}=300 \mathrm{MPa}$ and $E_{s}=210 \mathrm{GPa}$, and the properties of PT 
cables are $f_{y}=1560 \mathrm{MPa}$ and $E_{s}=195 \mathrm{GPa}$. The wall thickness and width are chosen according to reference (Pennucci et al. 2009). The height of all stories is considered to be 3500 $\mathrm{mm}$. The properties of the case study of base-rocking structures have been shown in Table $\mathbf{1}$. The geometrical properties and the pre-stressing ratio of bi-rocking structures are considered similar to the base-rocking ones. In bi-rocking systems, EDs are used at both the base and the middle-height rocking section. All EDs were designed by the assumption of $\lambda=1.25$. To isolate the rocking movement of the wall from the floor slabs, special details are considered as shown in Figure 8. The elongated bolt holes in detail of Figure 8a have been provided to allow transmission of seismic shears from the diaphragm to the rocking walls without preventing the free rocking of the core. Figure $8 \mathbf{b}$ and $8 \mathbf{c}$ show the section views of the connection in case of one-way and two-way slabs. Figure 9 shows the details of the proposed shear resistant connection of the rocking wall to the foundation or concrete retaining wall. Furthermore, key details of panel-to-panel joint of research of Brunesi et al. (2018) can be used to connect fixed panels to each other.

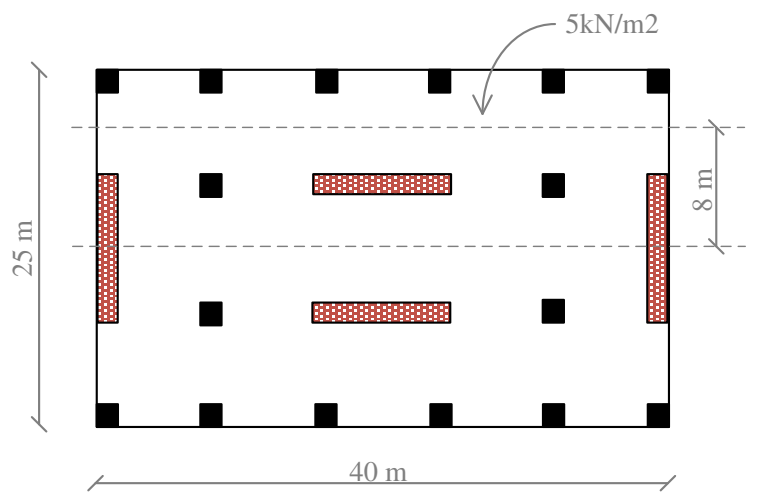

(a)

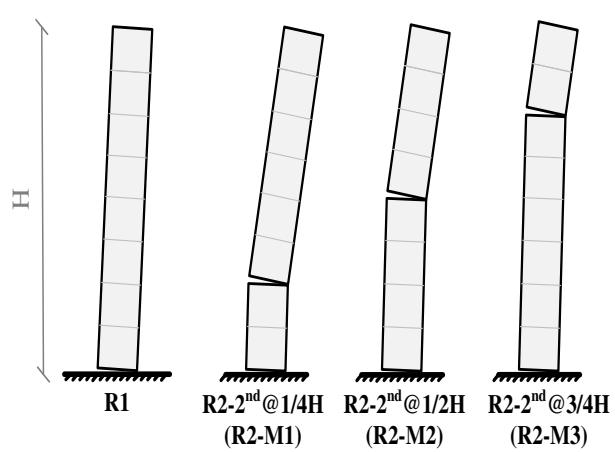

(b)

Figure 7. Specifications of the models: a) Plan view (Pennucci et al. 2009); b) Different types of rocking wall

Table 1. Properties of base-rocking wall structures (Pennucci et al. 2009)

\begin{tabular}{lccccc}
\hline Properties & 4 story & 8 story & 12 story & 16 story & 20 story \\
\hline Wall length $(\mathrm{m})$ & 4 & 6 & 7.5 & 8 & 8.7 \\
Wall thickness $(\mathrm{m})$ & 0.4 & 0.4 & 0.4 & 0.5 & 0.5 \\
Inter-story height $(\mathrm{m})$ & 3.5 & 3.5 & 3.5 & 3.5 & 3.5 \\
Wall axial load ratio & 0.04 & 0.06 & 0.09 & 0.10 & 0.12
\end{tabular}




\begin{tabular}{lccccc} 
Mild Steel Dampers (each side) & $16 \boldsymbol{\Phi} 30$ & $20 \boldsymbol{\Phi} 30$ & $24 \boldsymbol{\Phi} 30$ & $30 \boldsymbol{\Phi} 30$ & $38 \boldsymbol{\Phi} 30$ \\
Tendons (each side)* & 31 & 29 & 25 & 24 & 23 \\
Pre-stressing ratio of tendons & 0.34 & 0.54 & 0.52 & 0.59 & 0.63 \\
$d_{e d} / l_{w}$ & 0.35 & 0.35 & 0.25 & 0.35 & 0.35 \\
$d_{p t} / l_{w}$ & 0.125 & 0.125 & 0.125 & 0.125 & 0.125 \\
$l_{u b}(\mathrm{~m})$ & 0.2 & 0.4 & 0.6 & 0.6 & 0.6 \\
\hline
\end{tabular}

* each tendons has an area of $99 \mathrm{~mm}^{2}$
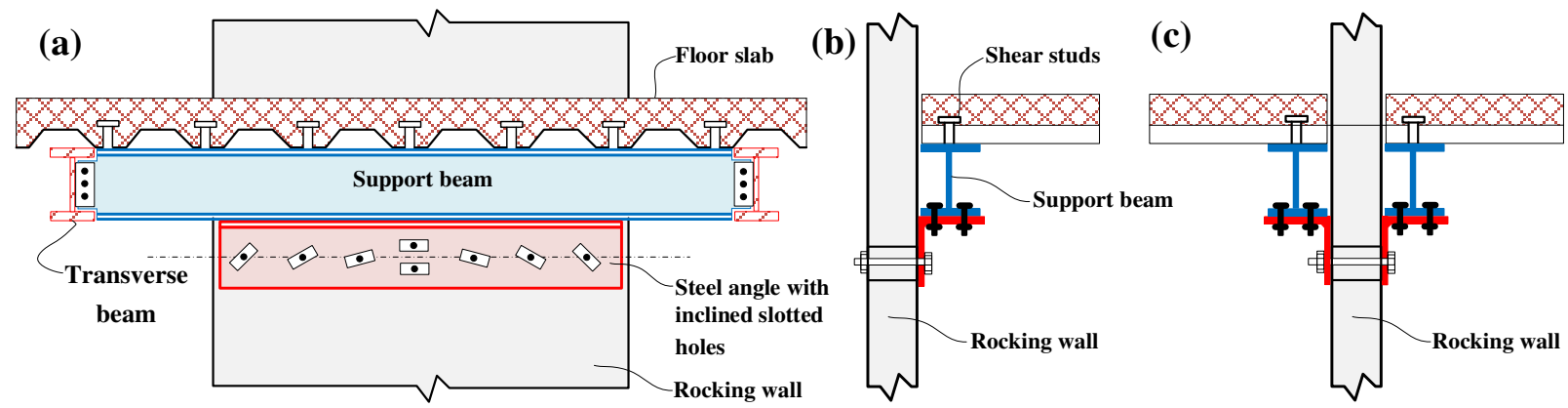

Figure 8. Detailing of the floor to rocking wall connections: a) front view (Grigorian et al. 2019); b) section, one way floor connection (Grigorian et al. 2019); c) section, two way floor connection
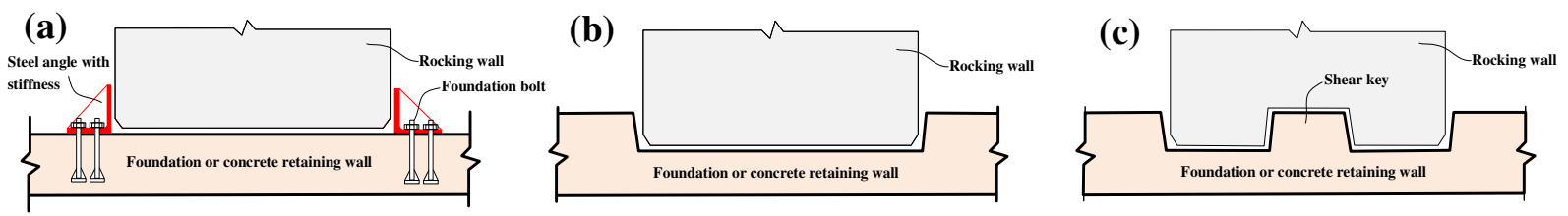

Figure 9. Detailing of the rocking wall to foundation connections: a) perimeter steel angle with stiffness;

b) wall grouted into foundation; c) wall grouted into foundation and using shear key

\subsection{Validation of the numerical modeling process}

In order to validate the process and assumptions of finite element modeling, the experimental test reported in Restrepo and Rahman (2007) is simulated. The specifications of the experimental sample are illustrated in Figure 10a. The wall thickness is $125 \mathrm{~mm}$. the compressive strength of concrete is $f^{\prime}{ }_{c}=45 \mathrm{MPa}$ (Figure 11). The properties of longitudinal and transverse reinforcement are $f_{y}=460 \mathrm{MPa}$ and $E_{s}=200 \mathrm{GPa}$ (Figure 11). The properties of PT cables are $f_{y}=1435 \mathrm{MPa}$ and $E_{s}=180 \mathrm{GPa}$ (Figure 11). 


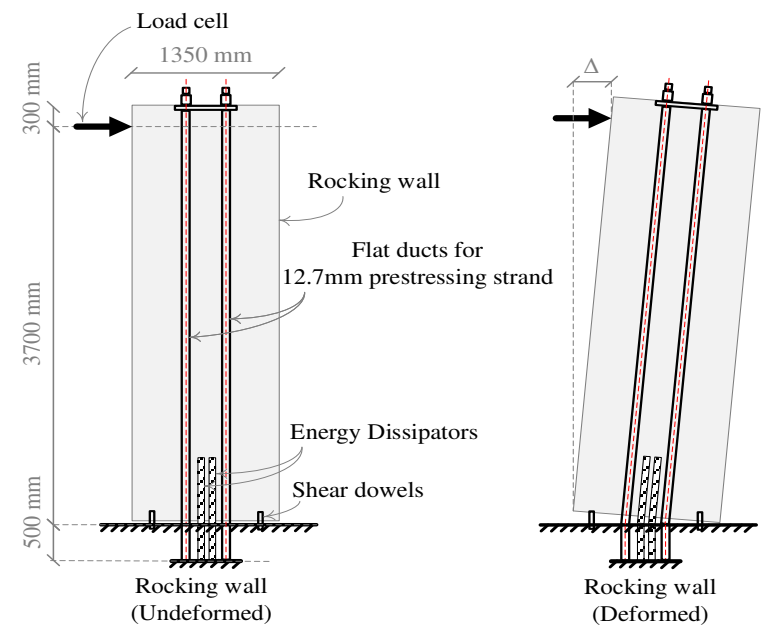

(a)

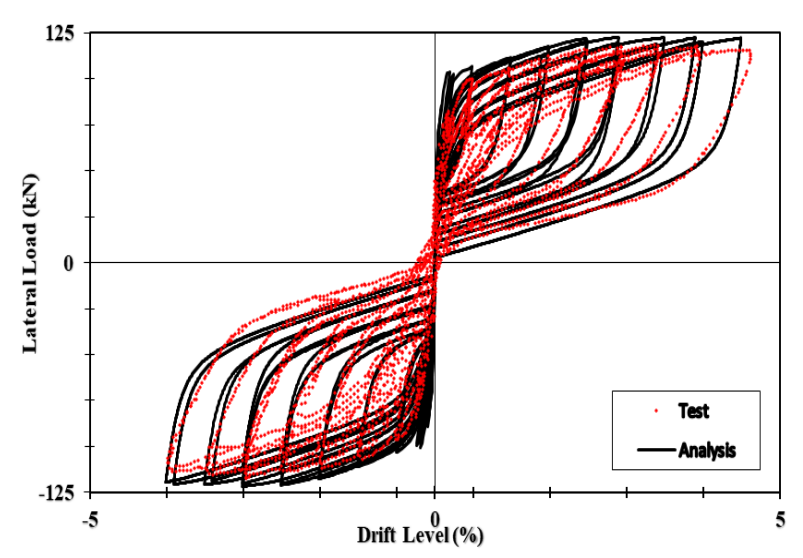

(b)

Figure 10. Validation of numerical modeling process: a) Specifications of experimental rocking wall sample; b) Numerical and experimental hysteretic curves of wall

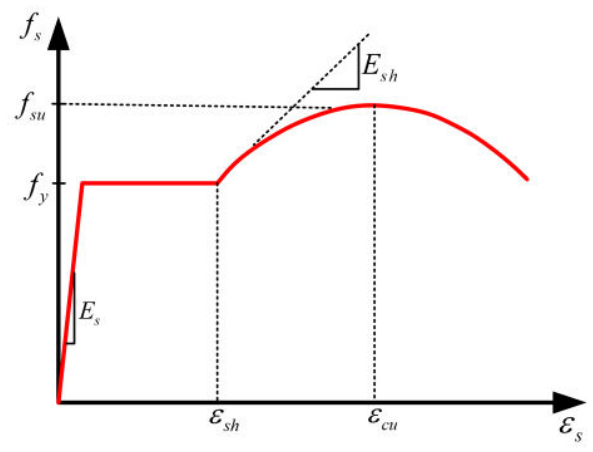

Material constants

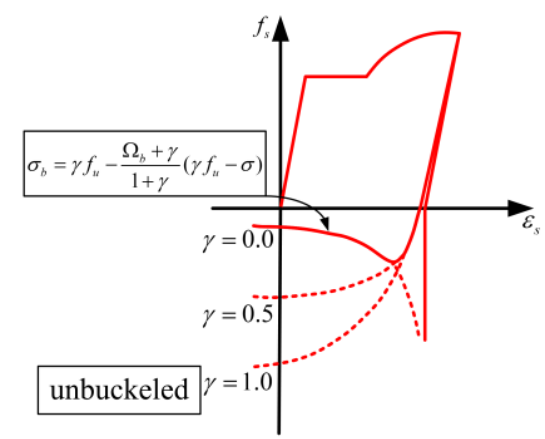

Buckling parameters

material Reinforcing Steel

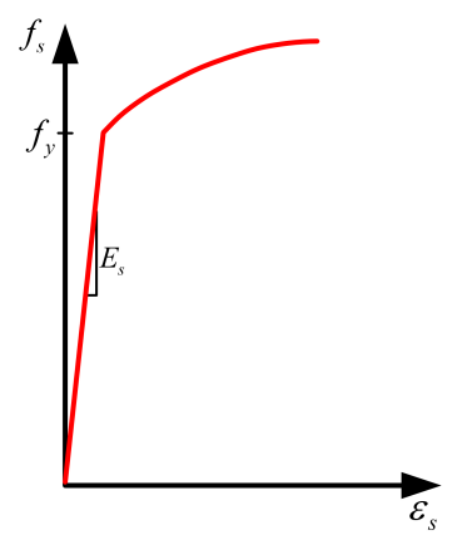

Cable

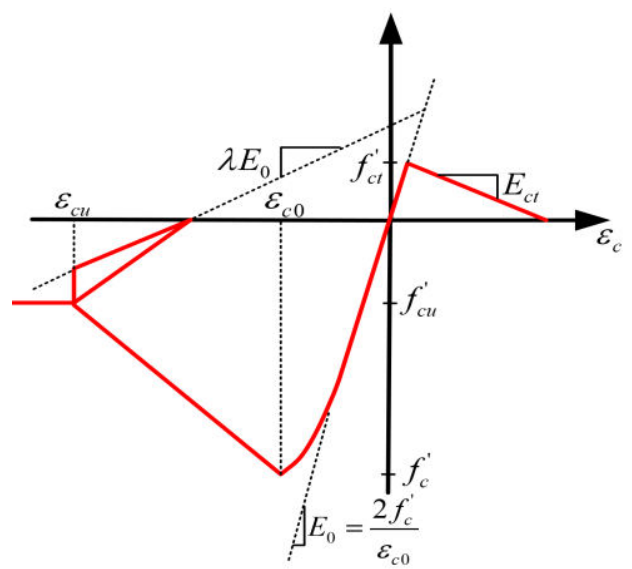

Concrete 02

Figure 11. Materials properties in finite element models 
When uplifting occurs in the rocking system, energy is dissipated by the rebars at the gap opening (Figure 10a). The numerical model is analyzed under the same cycling loading of the experimental counterpart according to Restrepo and Rahman (2007). Figure 10b compares the numerical and experimental curves of the base-shear against the displacement of the roof. The comparison indicates the appropriate accuracy of the modeling. The difference between the experimental and the numerical values of energy dissipation (the area under pushover curve) and the maximum base shear are about $6 \%$ and 3\%, respectively. These differences are quit negligible. Furthermore, a very small amount of residual drift is observed in the experimental model and no residual drift is observed in the numerical diagram. Therefore, the numerical model has an acceptable accuracy to simulate the physical model. It must be noted that the wall is simulated using a fiber section to account for nonlinear behavior. However, no concrete crushing is appeared. Therefore, it is possible to use an elastic section for the wall to reduce analysis time.

\subsection{Seismic records}

In this study, three sets of NF (pulse and no pulse) and FF records of FEMA-P695 (2009), including $22 \mathrm{FF}, 14 \mathrm{NF}$ (pulse), and $14 \mathrm{NF}$ (no pulse) records, were employed. To scale the seismic records according to the FEMA-P695 methodology, the records were first normalized. The normalization of records decreases the scattering caused by the scenario. This eliminates a part of the uncertainty called unwarranted variability (e.g., event magnitude, distance to source, source type, and site conditions) without changing the variation of frequency content of the records (FEMA-P695 2009). To normalize the records, the normalization of each record was calculated by dividing the median maximum velocity of the records (median $\left(P G V_{P E E R, i}\right)$ ) by the maximum velocity of $i$-th record $\left(P G V_{P E E R, i}\right)$, as follows:

$$
N M_{i}=\operatorname{median}\left(P G V_{P E E R, i}\right) / P G V_{P E E R, i}
$$

Since the horizontal records had two components and the analysis of this study was twodimensional, in the analysis, a horizontal record with a higher PGA value was used to determine the scale factor of FF records, and a vertical record perpendicular to the field was employed for the NF record (Archila 2014). In two-dimensional simulations, to scale the records, the average acceleration of the spectrum of the record is usually scaled to the design spectrum by ASCE7 
code (ASCE/SEI 72016 ) in the range of $0.2 T 1$ to $1.5 T 1$, where T1 is the time period of the first structure mode. After determining the spectral scale coefficient by comparing the median of the record spectrum and the code spectrum, the total scale coefficient of each record was determined by multiplying the spectral scale coefficient by the normalization coefficient $N M_{i}$.

\subsection{The higher mode properties}

Wiebe and Christopoulos (2015) and Rahgozar et al. (2018) used cantilever beam analogy for quantifying higher mode effects in multistorey buildings. They approximated the rocking wall response by combining the flexural and shear deformations of a cantilever beam. The higher the effective modal mass of the $n^{\text {th }}$ mode shape, the greater the effect of $n^{\text {th }}$ mode shape on the structural responses. The effective modal mass of each mode of self-centering rocking wall is defined as

$$
M_{n}^{*}=\Gamma_{n} \int_{0}^{H} \rho A \phi_{n}(z) d z
$$

where $\Gamma_{n}, \rho, \mathrm{A}$, and $\emptyset_{n}$ are the $n^{\text {th }}$ modal participation factor, the mass density, the cross-sectional area, and the $n^{\text {th }}$ mode shape, respectively. $\mathrm{H}$ and $\mathrm{z}$ are the total height and the height variable, respectively. This relation assumes a uniform mass distribution. The effective modal mass in each mode of the vibrated structure depends on the modal participation factor of the modes. The modal participation factor of the flexural deformation is defined as

$$
\Gamma_{n}=\frac{\int_{0}^{H} \phi_{n}(z) d z}{\int_{0}^{H} \phi_{n}^{2}(z) d z}
$$

The modal participation factor of shear deformation is defined as

$$
\Gamma_{n}=\frac{4\left(1-\cos \beta_{n} H\right)}{C_{n}\left(2 \beta_{n} H-\sin \beta_{n} H\right)}
$$

where the values of $\beta_{n} H$ for pinned-base and fixed-base condition is reported by Wiebe and Christopoulos (2015) and $C_{n}$ is an arbitrary constant that appears in the numerator of $\emptyset_{n}(z)$.

Increasing the height of the structure leads to increasing the modal participation factor of higher modes. On the other hand, increasing the modal participation factor of higher modes increases the structural responses. For example, increasing the modal participation factor of higher modes leads to an increase the total acceleration in higher modes. The total acceleration in mode $\mathrm{n}$ is 


$$
a_{n}(z, t)=\phi_{n}(z) \Gamma_{n} A_{n}(t)
$$

where $A_{n}(t)$ is the total acceleration of the SDOF system with the properties of mode $\mathrm{n}$. The spectral displacement at a period of $T_{n}$ and with the damping of mode $\mathrm{n}, S_{d}\left(T_{n}\right)$, is related to the pseudospectral acceleration, $\mathrm{Sa}\left(T_{n}\right)$, by

$$
S_{a}\left(T_{n}\right)=\omega_{n}^{2}(z) S_{d}\left(T_{n}\right)
$$

This is approximately equal to the maximum absolute value of $A_{n}(t)$, except for long periods or large damping (Wiebe and Christopoulos 2015).

Examining the above equations in rocking wall structures, it can be seen that in both shear and flexural beams, higher modes are very effective in creating: 1) roof displacement, 2) base shear, 3) mid-height moment, and 4) mid-height shear. In the next section, the effect of higher modes will be shown in the numerical models of self-center rocking wall systems.

\section{Results and discussion}

The results obtained will be discussed and summarized as follows: the effects of higher modes on the rocking walls, the effects of various seismic records on the rocking walls, the configuration of the bi-rocking walls, and the selection of the optimal bi-rocking section.

\subsection{Effects of higher modes on base-rocking walls}

To show the effects of higher modes on the rocking wall with a rocking base, the values of shear and moment demands caused by seismic records were compared to the design values. Figure 11 shows the values of the demands made in the 12-story structure compared to the design values of this structure. Moment Max. and Shear $_{\text {Max. }}$ respectively show the maximum moment and maximum shear over time for each record (Figure 12). As demonstrated in Figure 12, the amount of moment and shear of the walls under seismic records increases sharply compared to the design values. Since the design was based on the first mode, the demands are estimated to be unrealistic and may increase the vulnerability of the structure while an earthquake occurs. The increase of demand in the cores of the structure compared to the design mode might be due to neglecting the effects of higher modes. Given that the configuration of the rocking cores could be adjusted in a wat that their shear and moment diagrams would become more similar to the design state, a safer design might be established. These effects increased with the number of stories indicate the contribution rate of higher modes. As stated before, the stiffness of the system after 
the full yielding of ED elements, is considered in the current study. This stiffness is due to the elastic stiffness of the cables and the secondary stiffness of the base ED elements (Figure 5b). Therefore, when the earthquake intensity is increased, the moment at the base and in middle height of the core increases due to higher mode effect.
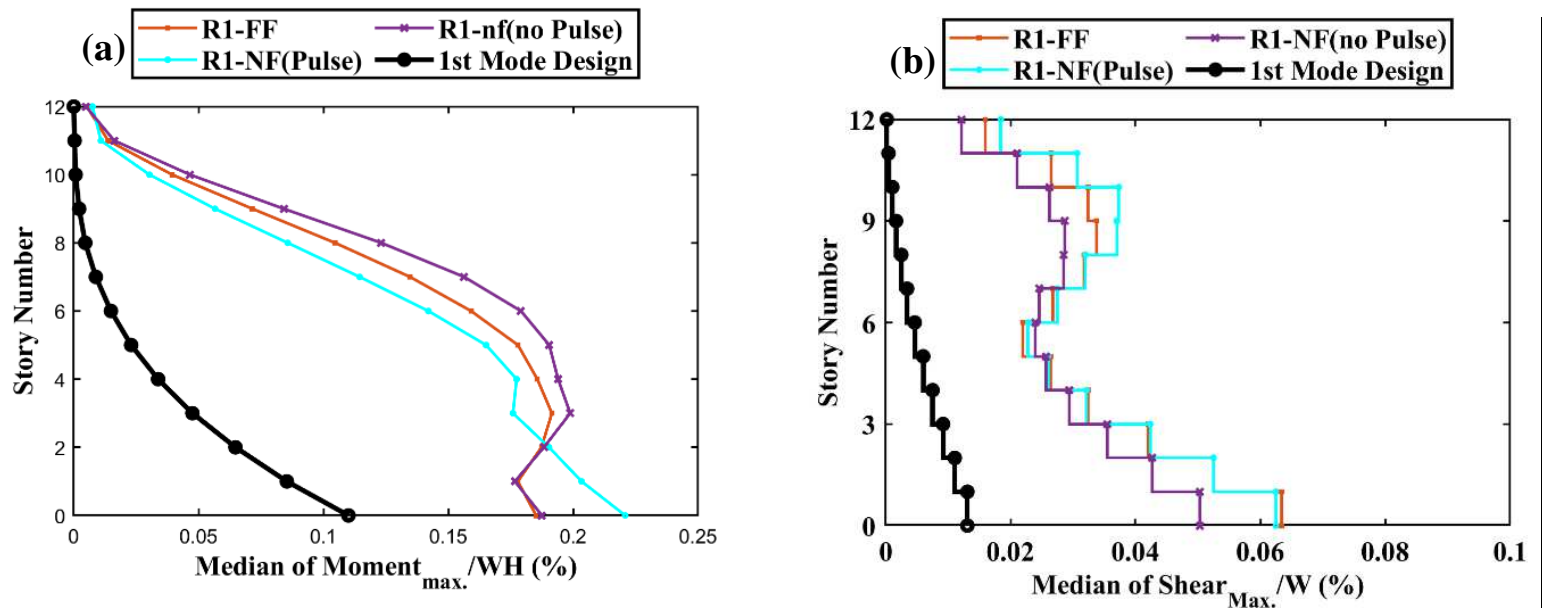

Figure 12. Comparison of demands made in the wall under different seismic records with design values

\subsection{Effects of various seismic records on base-rocking walls}

The design method selected based on the direct displacement method (Pennucci et al. 2009) and under NF (pulse) records did not give the desired result, and the maximum inter-story drifts

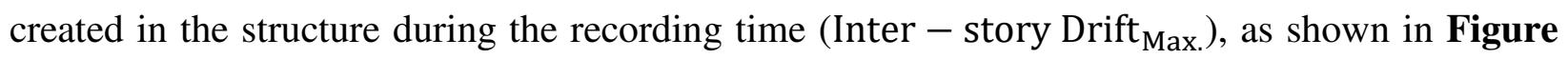
13, has exceeded the design limit (2\%) (Pennucci et al. 2009). The structures with 4, 8, 12, and 16 stories under FF and NF records and structures with 4, 8, and 12 stories under NF (no pulse) records had given the desired result and the maximum drift values of the stories has not exceeded the design limit (2\%). The drift of 16-story structures under NF (pulse) records and 20story structures under NF (no pulse) and FF records have exceeded the code value; therefore, this design method is not appropriate for these structures.

As it can be seen in Figure 13, in all the structures, NF (pulse) records generate more drift responses in the structures. In shorter structures, i.e. with 4 and 8 stories, NF (no pulse) records generate more drift responses in the structures compared to FF. While, the selected middle structures with 12 and 16 stories, compared to FF and NF (no pulse) records can be critical in different stories of each of these two types of records. In a high-rise structure with 20 stories, FF records generate more drift responses in the structure than NF (no pulse) records. 

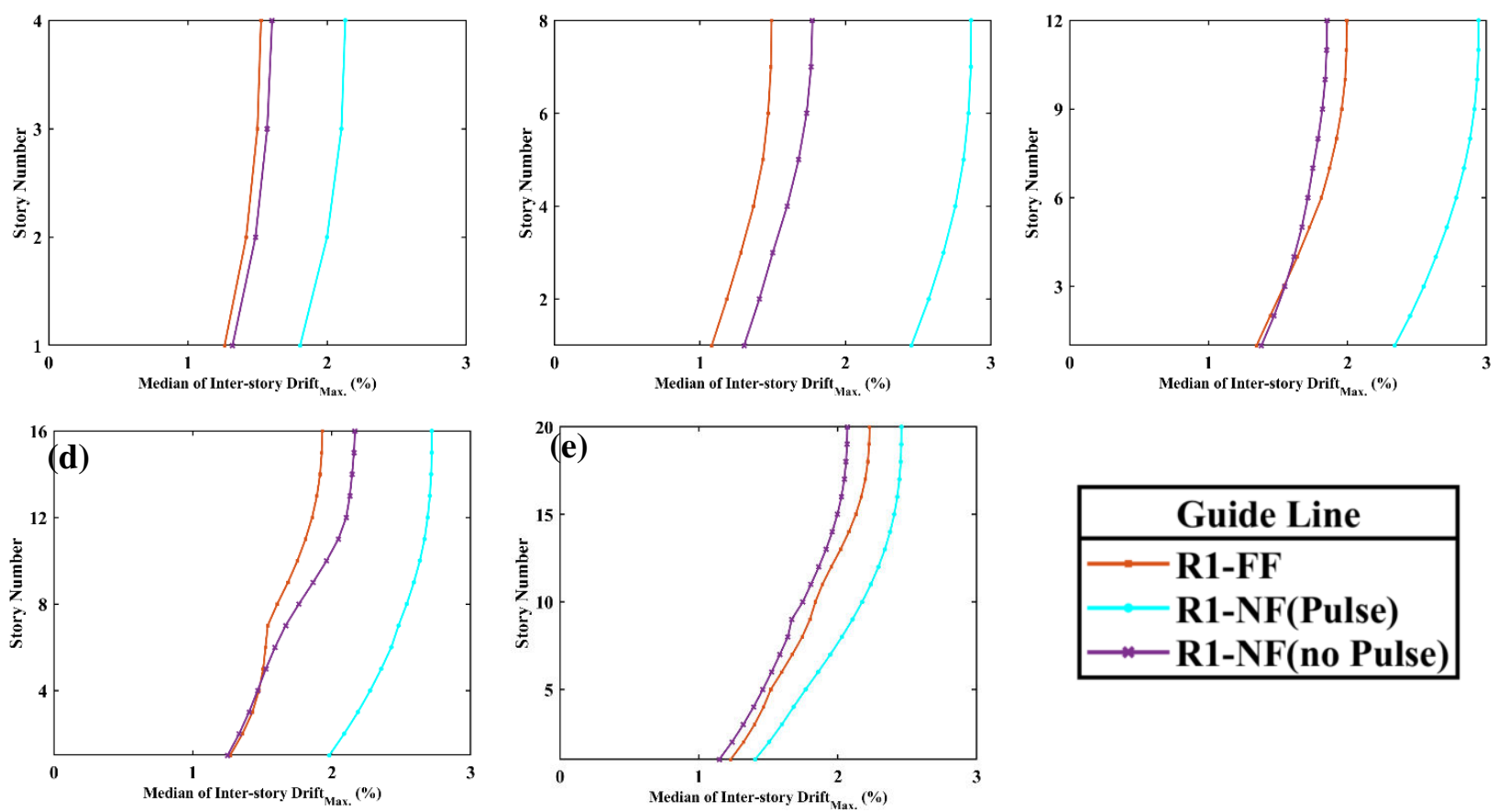

Figure 13. comparison of Inter - story Drift ${ }_{M a x}$ under different seismic records of structures; (a) 4story, (b) 8-story, (c) 12-story, (d) 16-story and (e) 20-story

According to Figure 13, the responses of structures under different types of ground motions (FF, NF Pulse, and NF- no Pulse) were different. The reason behind this is that the frequency content of ground motions and dynamic specification of structures are different. Figure 14 shows Fourier curves for three unscaled records selected as representatives of three ground motion types. The Fourier amplitude of Northridge-NF (Pulse) in each period is more than other ground motions. As expected, the inter-story drifts of structures under NF (Pulse) are more than other ground motions. According to Figure 14, the Fourier amplitude varies over the period interval. So, each structure is expected to show a different seismic response depending on its frequency content. For example, the principal natural period of 12-story structure is $1.442 \mathrm{sec}$. So, using Fig. 13, the corresponding Fourier amplitudes of Landers-FF, Cape Mendocino-NF (no Pulse), and Northridge-NF (Pulse) are 0.088, 0.087, and 0.343. If the scaled amplitudes according to the target design spectrum are calculated, the following values are obtained correspondingly: 0.21 , 0.10 , and 0.39 . These values well justify the relative values of inter-story drifts of the considered structure under different ground motions. As another example, the corresponding scaled Fourier amplitudes for the 16-story structure are $0.11,0.14$, and 0.23 . Similarly, a direct relation between these values and the inter-story drifts of this structure is seen. 

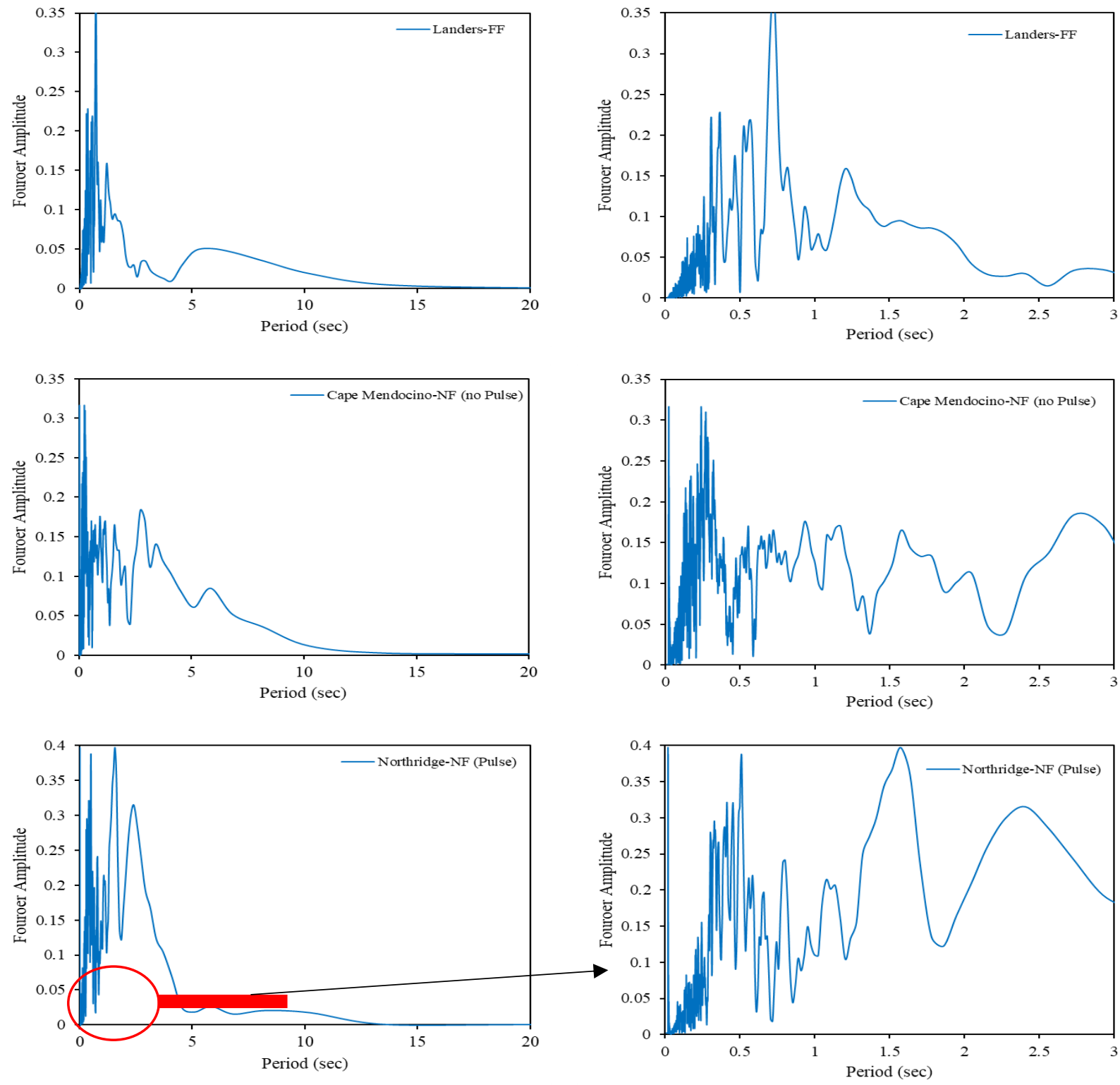

Figure 14. The unscaled Fourier amplitude of different single ground motions (enlarged diagrams for the periods of 0-3 sec are shown on the right)

Figure 15 shows the median values of maximum moment $\left(\right.$ Moment $_{\text {Max. }}$ ) normalized by the product of the building weight and height $(\mathrm{W} * \mathrm{H})$ in different stories. In taller structures, the effect of higher modes increases the moment in the middle floors than the base. The higher the structure, the more the effects of higher modes cause moment demands in the rocking core. These demands, which may be ignored in the design, cannot be predicted by static analysis and result in unwanted damage to the core of the structure. As the structures under different records in Figure 15 show, the effects of higher modes are higher in the NF and FF (pulse) records, and 
more moment demands can be observed in the height resulting from these two types of records. In this case, in all structures except the twenty-story structure, NF (no pulse) records are more critical in terms of creating moment demands in the structure.
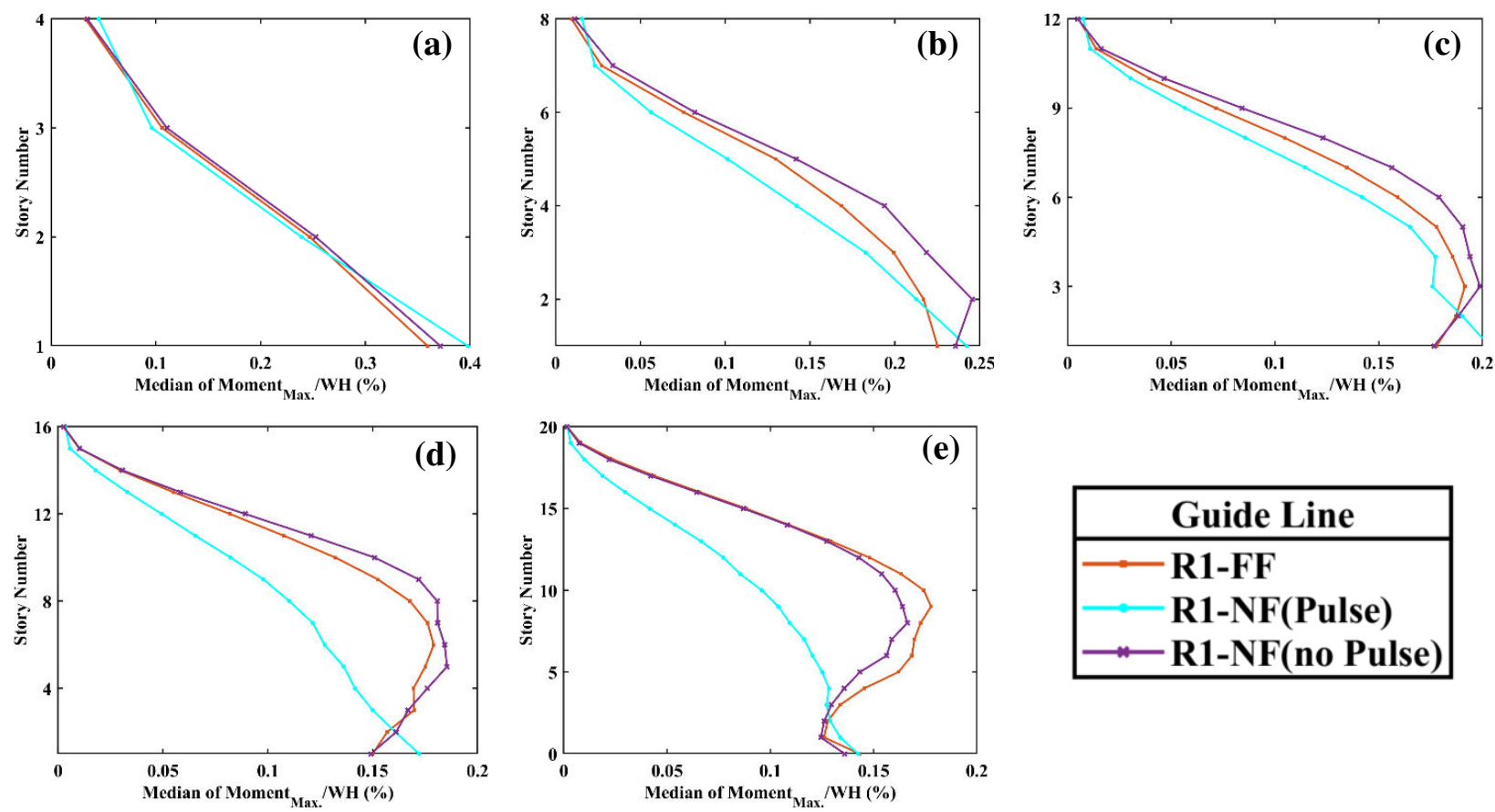

Figure 15. Comparison of the median maximum moment of a wall under different seismic records of structures; (a) 4-story, (b) 8-story, (c) 12-story, (d) 16-story, and (e) 20-story

Figure 16 shows the median values of maximum shear $\left(\right.$ Shear $_{\text {Max. }}$ ) normalized by the total weight of the wall in different stories. Shear ${ }_{\text {Max }}$ of the short walls of 4 and 8 stories do not follow a specific pattern; however, in the middle and high-rise structures, the Shear $r_{\text {Max }}$. in the lower stories is always higher under FF records and in the upper stories is higher under NF (pulse) records. Furthermore, the shear created due to NF (no pulse) records is always less than the two wall states under FF and NF (pulse) records.
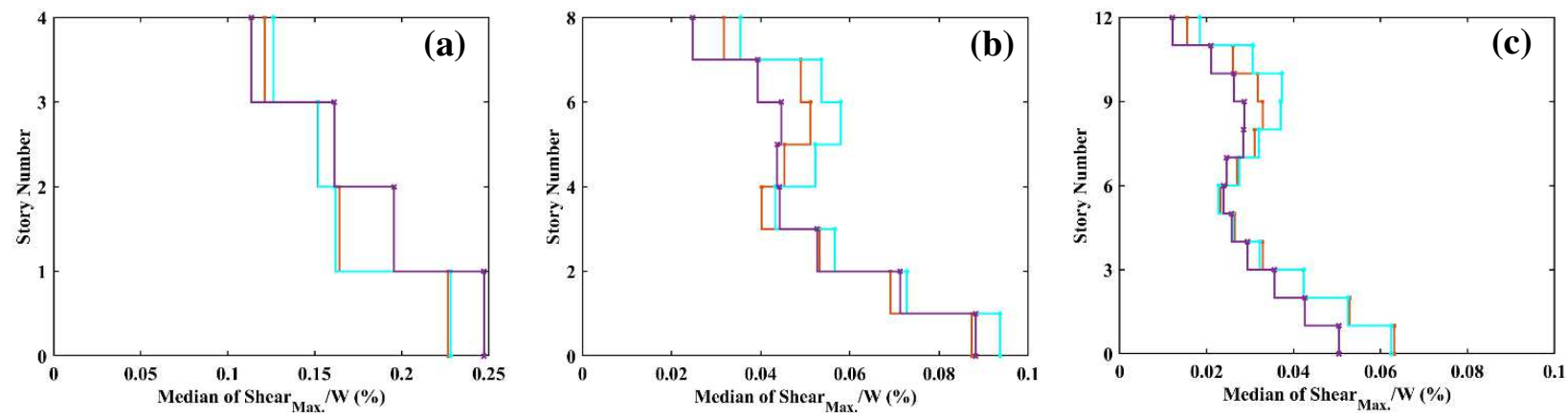

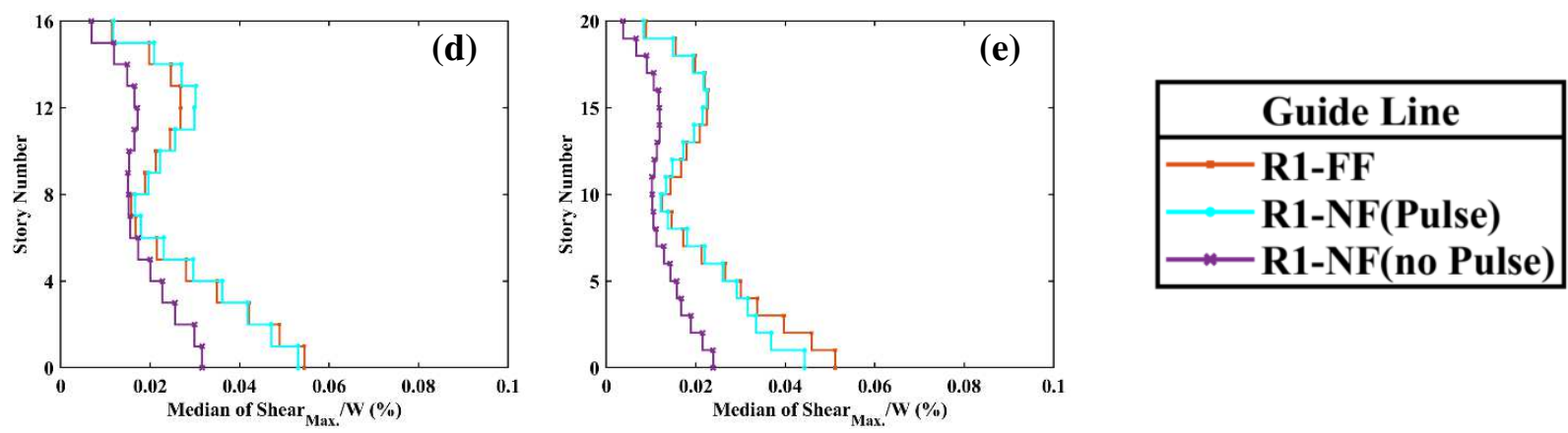

Figure 16. Comparison of the median maximum shear of a wall under different seismic records of structures; (a) 4-story, (b) 8-story, (c) 12-story, (d) 16-story, and (e) 20-story

Figure 16 shows the modal spectral accelerations of R1 wall under different seismic records for the first three modes. It is expected that the effect of higher modes has a direct relation with their spectral acceleration ( $\mathrm{Sa}$ ). In this regard, the moment demands of R1 walls in FF and NF (no Pulse) ground motions (illustrated in Figure 15) were increased due to high Sa values of higher mode (mode 2 and 3). It is also interesting that according to Figure 17, the Sa of mode 2 and 3 under FF and NF (no Pulse) ground motions has a strong direct relation with the height of the structure. For this reason, as seen in Figure 15, the effects of high modes on the moment demand is more significant in high-rise structures in these two types of ground motions. On the other hand, in NF (Pulse) ground motions, the Sa vales of high modes are not high (Figure 17). Therefore the structure under this ground motions does not experience significant high mode effect on the moment (Figure 15).

Usually, the base shear of R1 wall mainly depends on the amount of Sa of the first mode and the higher modes are less effective on the maximum base shear. So, as Sa of the first mode increases, the base shear in the rocking system increases. This can be observed by considering Figures 16 and 17. As seen in Figure 16(a), the base shear of the 4-story model under NF (no Pulse) is higher relative to other ground motions. Simultaneously, the Sa of this structure under NF (no Pulse) is higher relative to its Sa under the other ground motions. On the other hand, in taller structures, the Sa under FF and NF (Pulse) is higher than NF (no Pulse). 


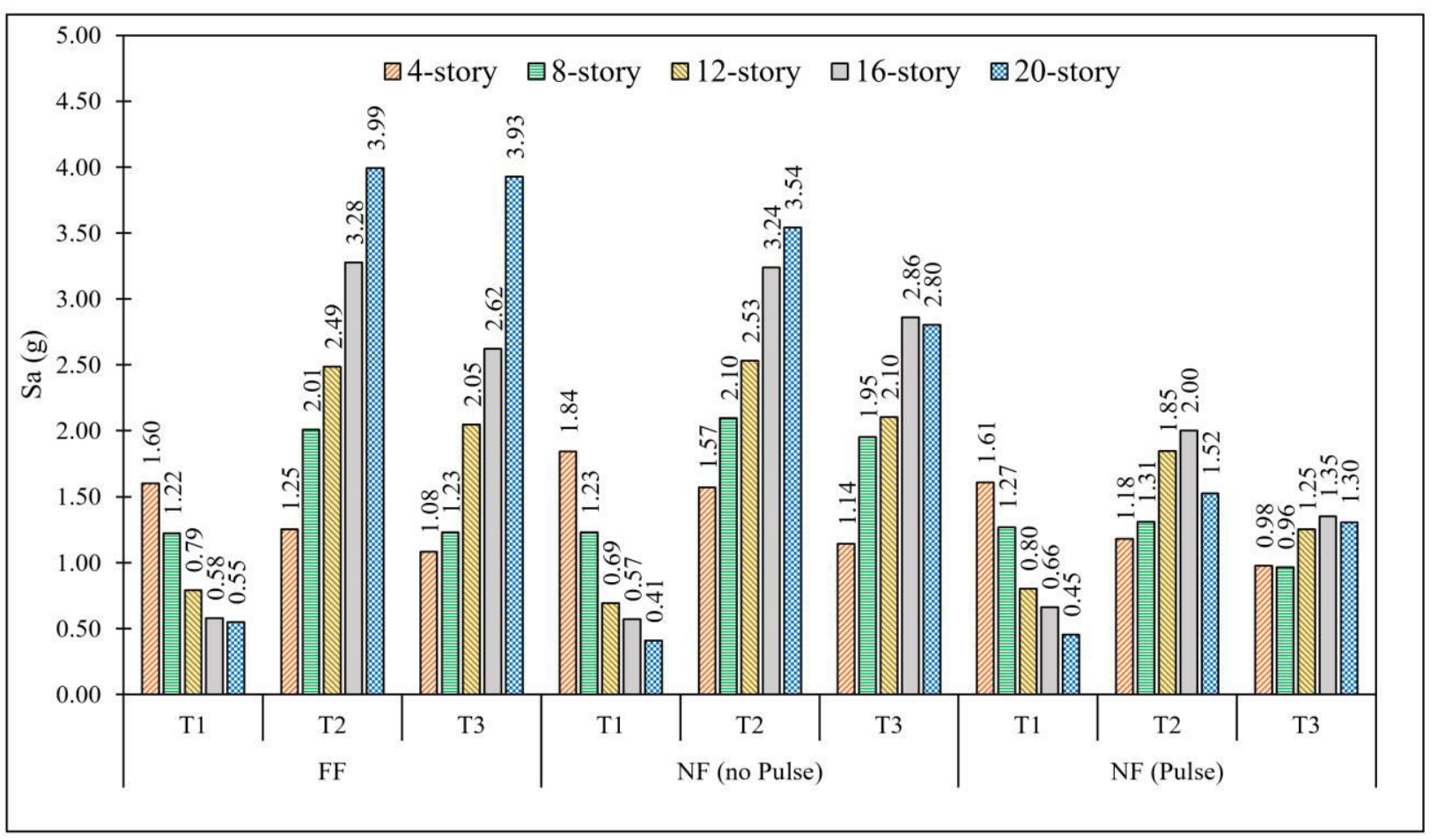

Figure 17. The modal spectral accelerations of R1 walls under different seismic records

\subsection{Seismic response of bi-rocking walls}

The employment of rocking sections at height is one of the solutions to reduce the effects of higher modes in rocking structures. One may considers different locations of the rocking section at the wall height (Figure 7b). The effects of higher modes in the 20-story bi-rocking wall system compared to base-rocking system are shown in Figure 18 and 19. As seen in these figures, the maximum normalized Moment Max. $_{\text {and }}$ Shear ${ }_{\text {Max }}$ is created at the middle of the core height and at the base of the core, respectively. Furthermore, bi-rocking systems have less responses than the base-rocking ones in terms of the maximum Moment $_{\text {Max. }}$ and Shear Max. The $_{\text {. The }}$ reason behind this is that the moment capacity at the second rocking block is a specified constant and cannot be increased. On the other hand, the reason of reduced shear under seismic record is using the EDs at the second rocking block. It is noteworthy that, the effectiveness of bi-rocking walls in reducing the moment and shear demands under FF and NF (no Pulse) is more than NF (Pulse). Furthermore, the reduction of the demands depends on the location of the second rocking section. 

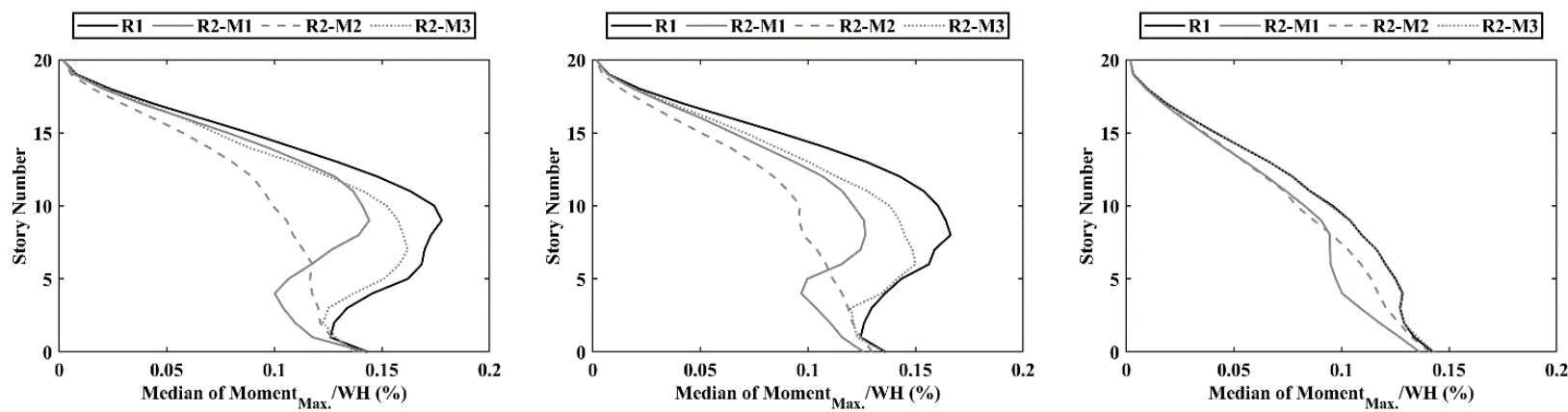

Figure 18. Comparison of the median maximum moment created in the 20 -story base-rocking and birocking walls under different seismic records; (A) FF, (b) NF (no Pulse), and (c) NF (Pulse)
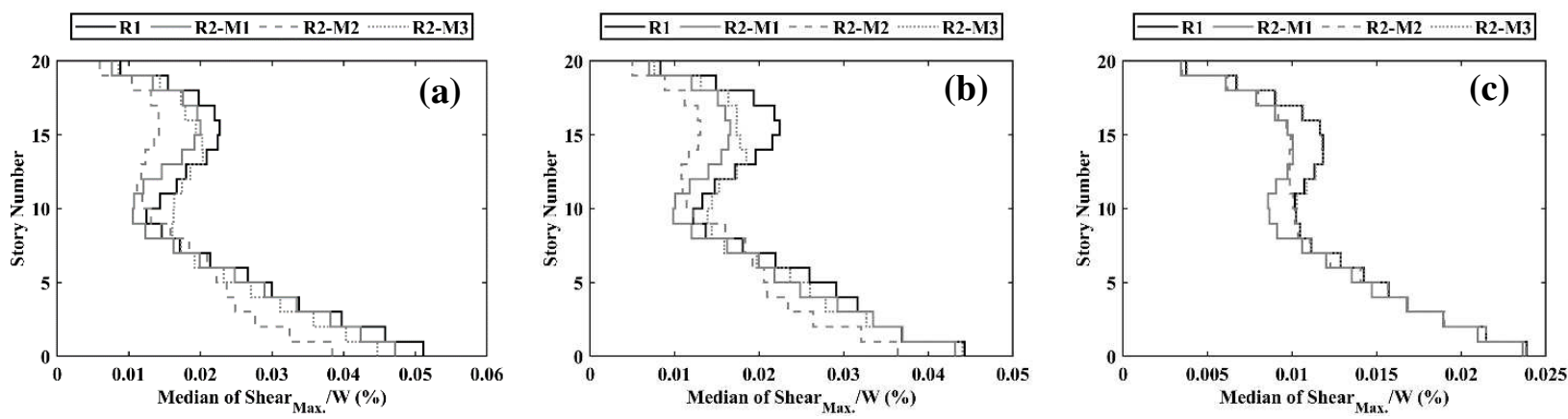

Figure 19. Comparison of the median maximum shear created in the 20-story base-rocking and birocking walls under different seismic records; (a) FF, (b) NF (no Pulse), and (c) NF (Pulse)

Figure 20 demonstrates the median Inter - story Drift ${ }_{\text {Max. }}$ of a 20-story structure. According to this figure, rocking sections do not have much effect on the changes in drifts created in stories under NF (pulse) records, and these changes are greater at NF (pulse) records compared to NF (no pulse) records. As seen in this figure, in bi-rocking walls, the inter-story drifts are increased intensively at two stories (corresponding to the two rocking sections). While in base-rocking walls, this happens once (in the first story only). As stated before, the higher mode effect in birocking walls under FF and NF (no pulse) is higher than NF (pulse). This phenomenon is clearly detected in Figure 20.

Figure 21 shows the maximum Inter - story Drift ${ }_{\text {Max. }}$ of the considered structures. As indicated in Figure 21, bi-rocking structures under the 3-type seismic recodes have a greater maximum value of Inter - story Drift ${ }_{\text {Max. }}$ compared to the rocking wall system. In this kind of wall, under NF (pulse) records, more inter-story drift values are observed compared to other two types of seismic records. 

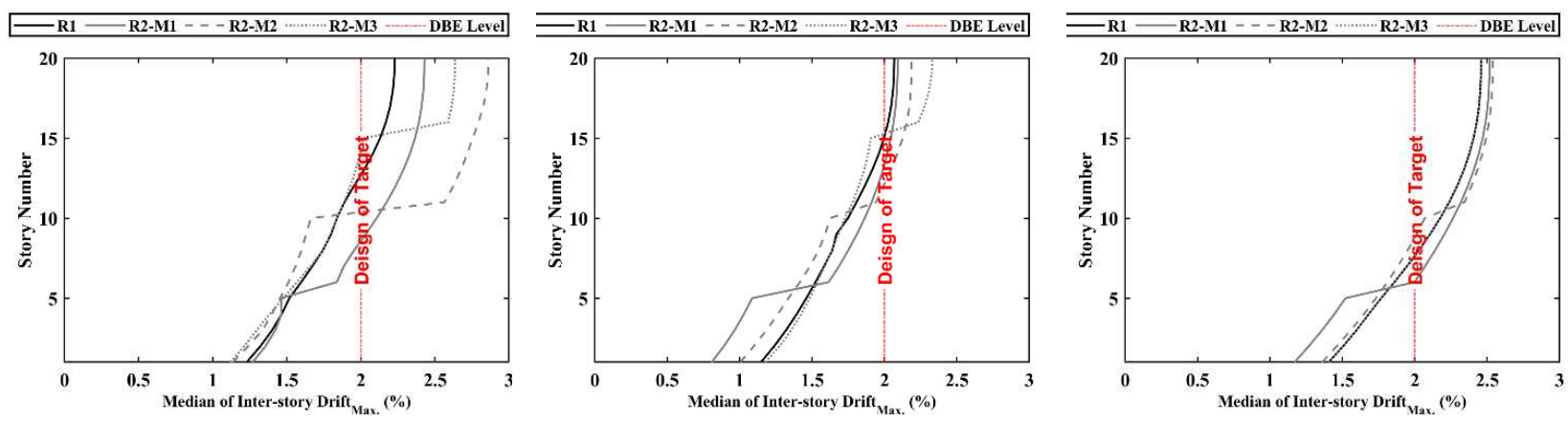

Figure 20. Comparison of median Inter - story Drift Max. $_{\text {in }}$ the 20 -story base-rocking and bi-rocking walls under different seismic records; (a) FF, (b) NF (no Pulse) and (c) NF (Pulse)

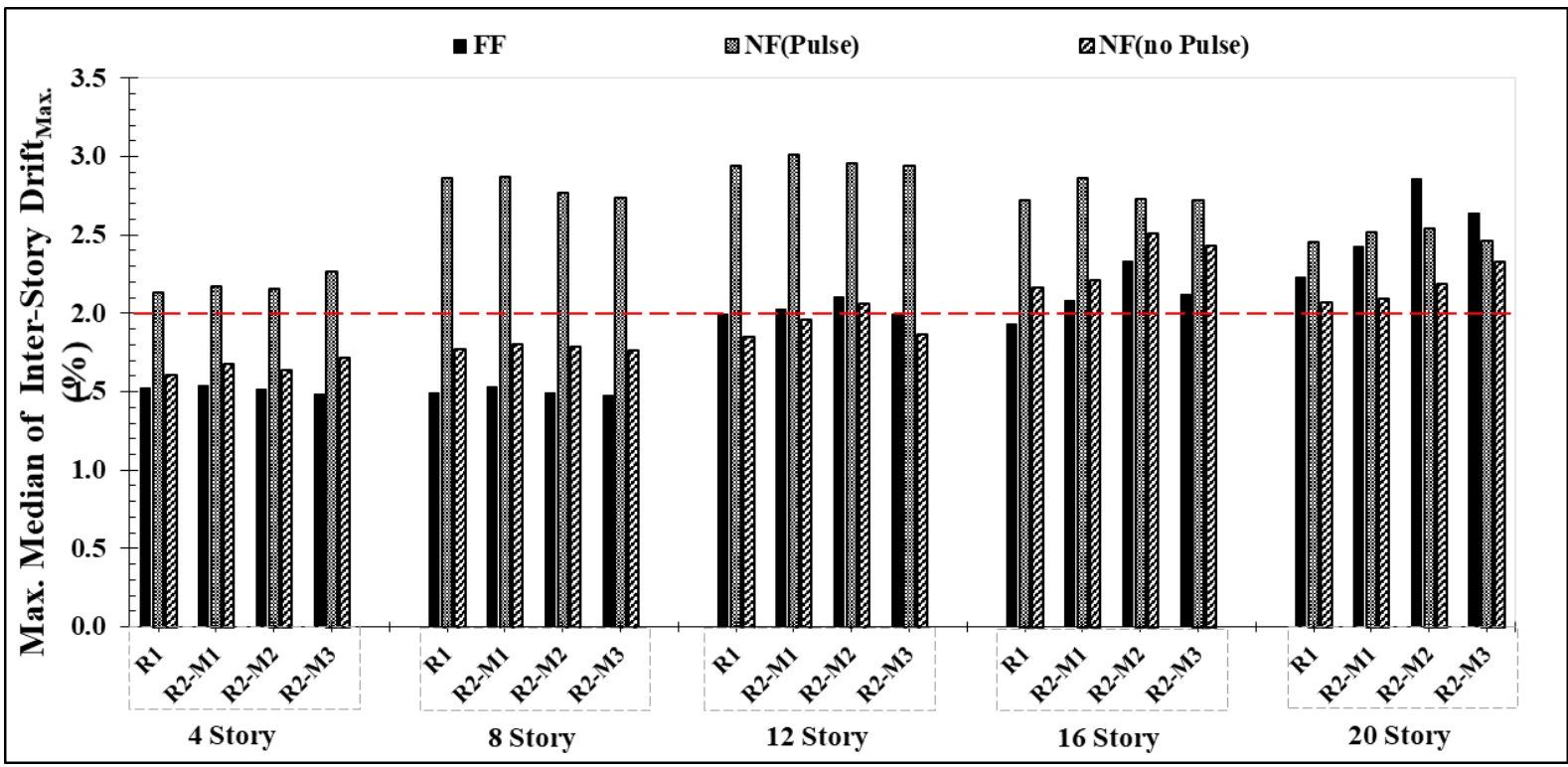

Figure 21. Comparison of maximum Inter - story Drift ${ }_{\text {Max. }}$ of rocking and bi-rocking walls of floors under different seismic records

Given the comparison of the median values of inter-story residual drift in structures, it can be said that although the maximum value is slightly higher for bi-rocking walls compared to the simple ones, there is not much difference in the maximum values for rocking and bi-rocking walls. The values of the inter-story residual drift for a 20-story structure are shown in Figure 22. According to Figure 22, the values of inter-story residual drift are greater for FF, NF (no pulse), and NF (pulse) records, respectively. The examination of residual drift in other structures, demonstrated in Figure 23, show that as the height of the structure increases, the maximum of inter-story residual drift of stories accordingly increases. As shown in Figure 23, in high-rise structures, the effect of FF records on the increase of residual drifts is more than NF records. In low-rise structures, NF (pulse) records are more critical than FF and NF (pulse) records. 
Therefore, the residual drifts can be neglected in the rocking systems under study, and after the earthquake, the structure can be restored to its original location with minimal preparation.
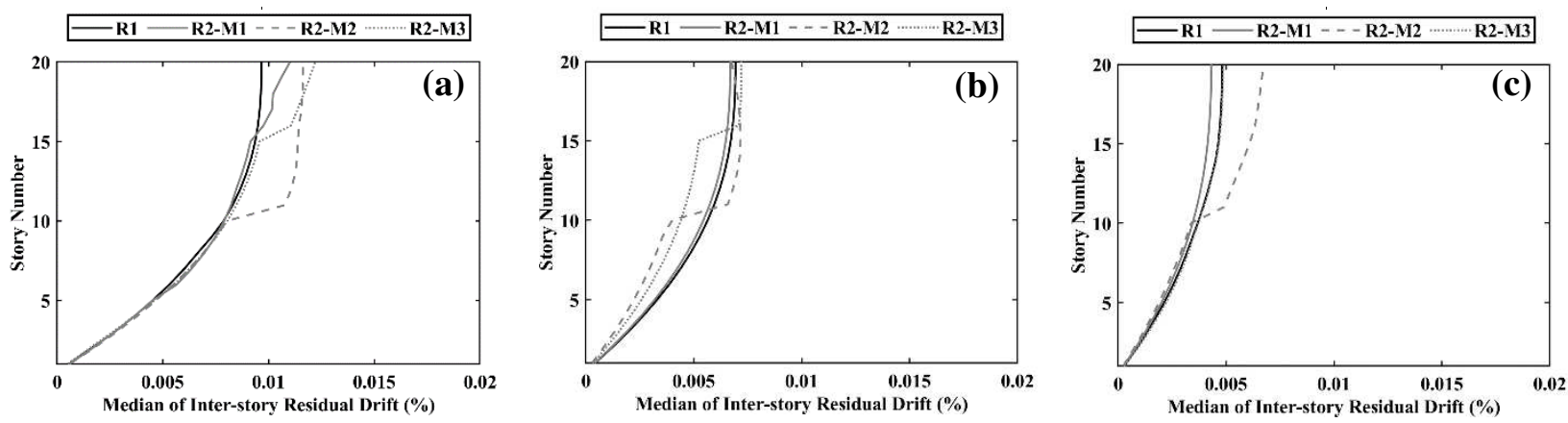

Figure 22. Comparison of the residual inter-story drift of the 20-story base-rocking and bi-rocking walls under different seismic records; (a) FF, (b) NF (no Pulse) and (c) NF (Pulse)

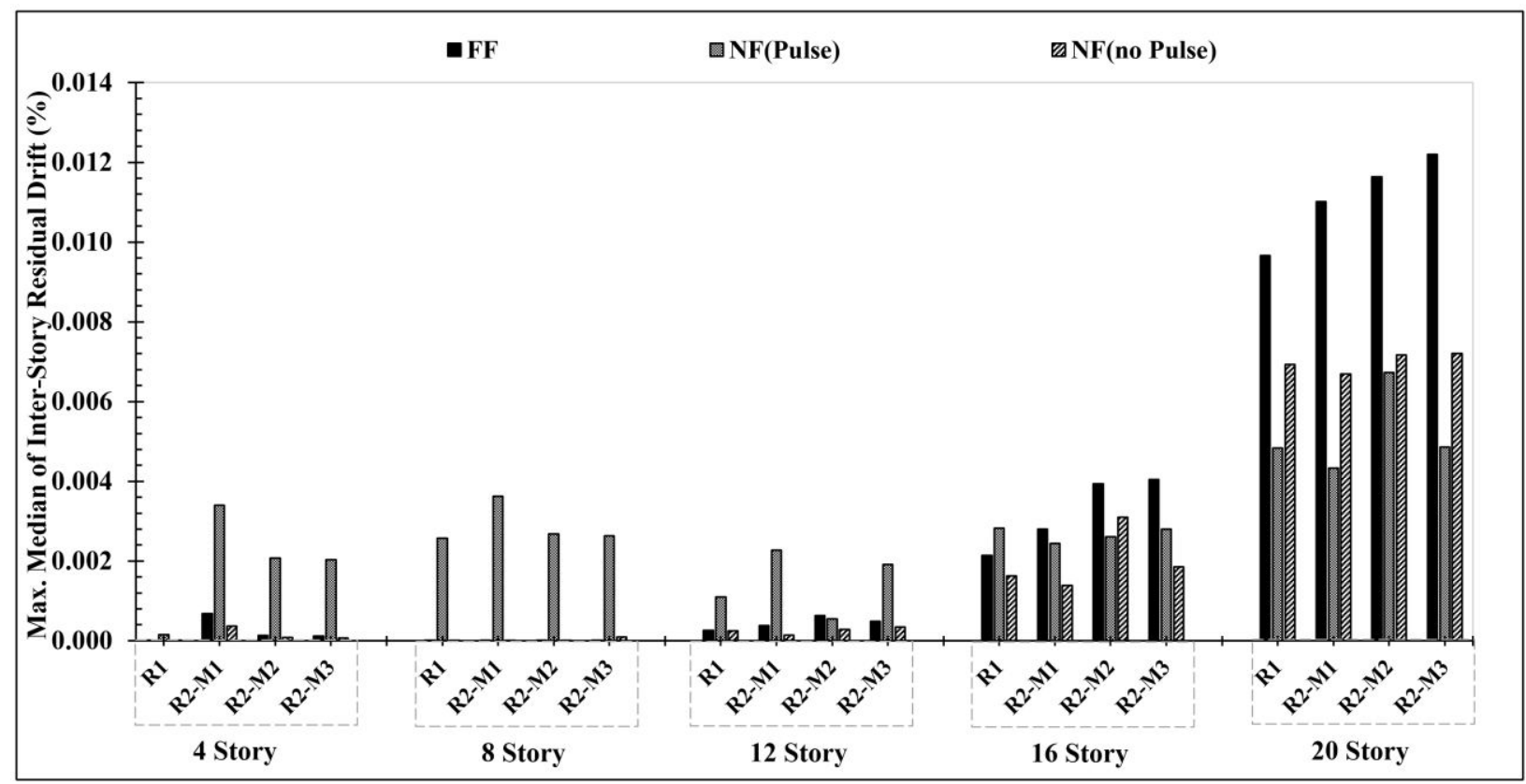

Figure 23. Comparison of the maximum median of inter-story residual drift of rocking and bi-rocking walls of floors under different seismic records

It is noteworthy that the residual and the maximum inter-story drifts are not interdependent in rocking systems. For example, Figure 13(e) shows that the median inter-story drifts of the R1 20-story structures are larger under NF (pulse) records. On the contrary, Figure 22 and Figure 23 show that the R1 structures type exhibits larger median inter-story residual drifts under FF records. For further explanation, the time-history curves of roof inter-story drift of the R1 20- 
story structure corresponding to three separate records are shown in Figure 24. The records are the same as the one in Figure 14 for R1 structures. It must be noted that the maximum and the residual inter-story drifts happen in roof story. According to Figure 24, the maximum inter-story drift of the considered representative records for FF, NF (no pulse), and NF (pulse) are 1.44, 1.5, and $1.5 \%$, respectively. Whereas, the corresponding residual inter-story drifts are 0.008, 0.0008, and $0.0002 \%$, respectively. Then, in an approximately equal maximum inter-drift under seismic ground motions, the residual drift can be different so that the maximum value occurs in the FF record. Furthermore, the residual drift under NF (no pulse) is greater than the residual drift under NF (pulse). Generally, the maximum inter-story drift and the residual inter-story drift in the rocking structures are not proportional under different ground motions.
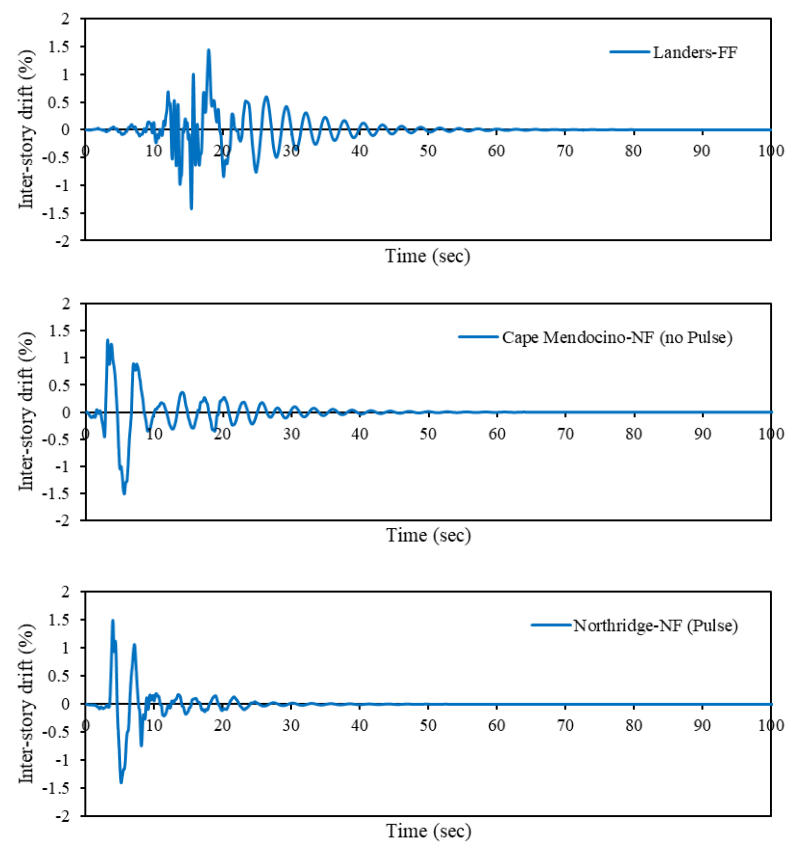

Figure 24. Comparison of the inter-story drift of roof story of 20-story structure under single seismic ground motions

The median of the maximum drift of roof during records (Roof Drift $_{\text {Max. }}$ ) was also examined for the effects of records and bi-rocking cores. Figure 25 shows the maximum Roof Drift $t_{\text {Max. }}$ of floors for the examined structures under different seismic records. According Figure 25, the effect of NF (pulse) records in increasing the amount of roof drift is more than other records, 
which can be seen more clearly on stories 8,12 , and 16 . Furthermore, the roof drifts are equal under the NF (no pulse) and FF seismic records.

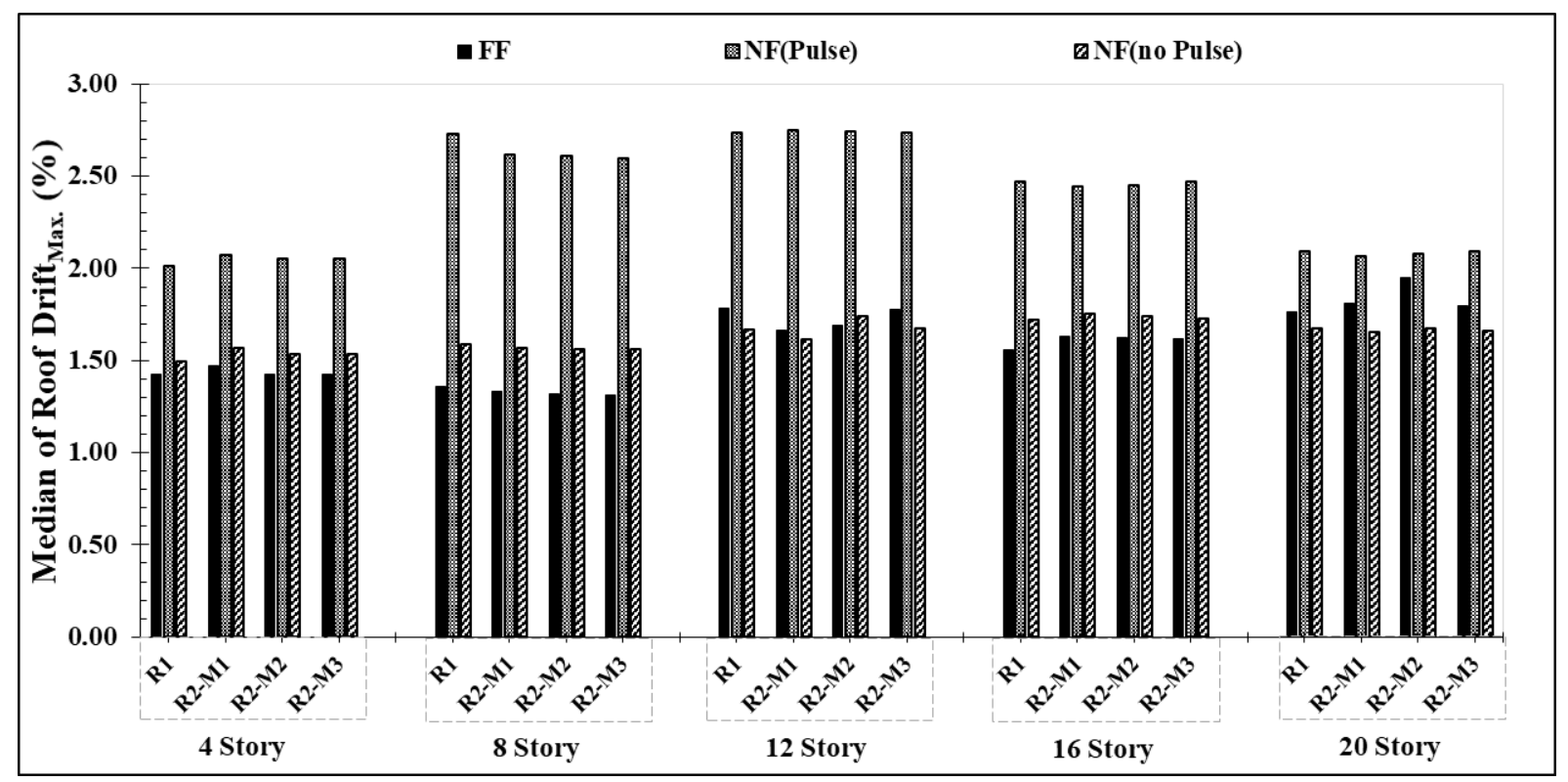

Figure 25. Comparison of median Roof Drift $t_{\text {Max. }}$ of rocking and bi-rocking walls under different seismic records

\subsection{Selecting the optimal bi-rocking section}

Since a different configuration to Figure $\mathbf{7 b}$ was considered in this study, and the structures were applied under different seismic records, the optimal state of bi-rocking systems compared to the rocking systems was determined. To this end, the percentage of the reduction of the higher modes effects in terms of the moment and shear of bi-rocking walls compared to rocking walls were examined. Figure 26 and 27 show the percentage of the moment and shear reduction by doubling the rocking walls. According to Figure 26, while using bi-rocking would be effective in FF and NF (no pulse) records as well as increasing the height of structures, it is not effective in reducing the demands of rocking walls under NF (pulse) records and shorter structures. 


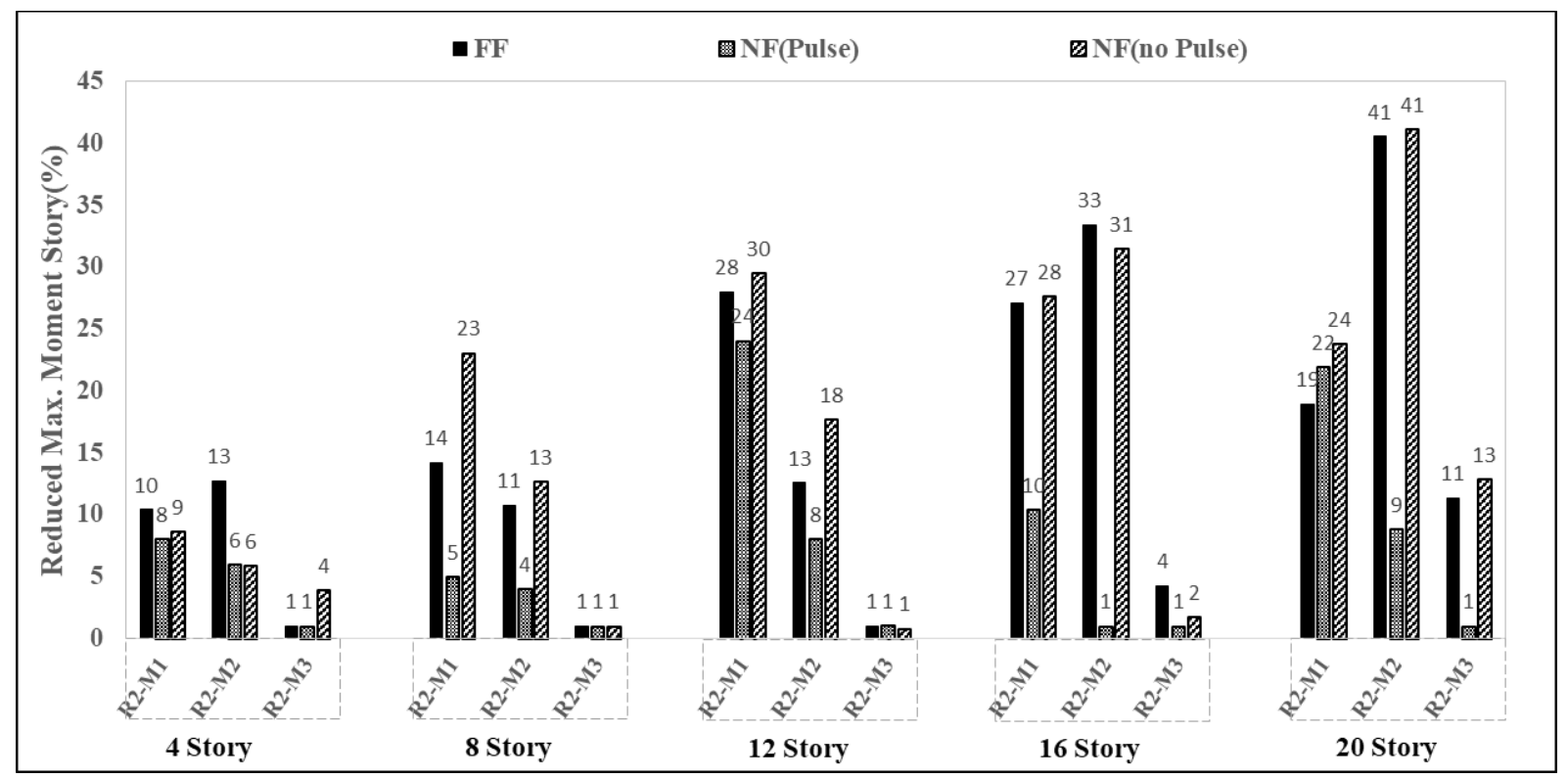

Figure 26. Percentage of the moment reduction in bi-rocking walls compared to the simple walls under different seismic records

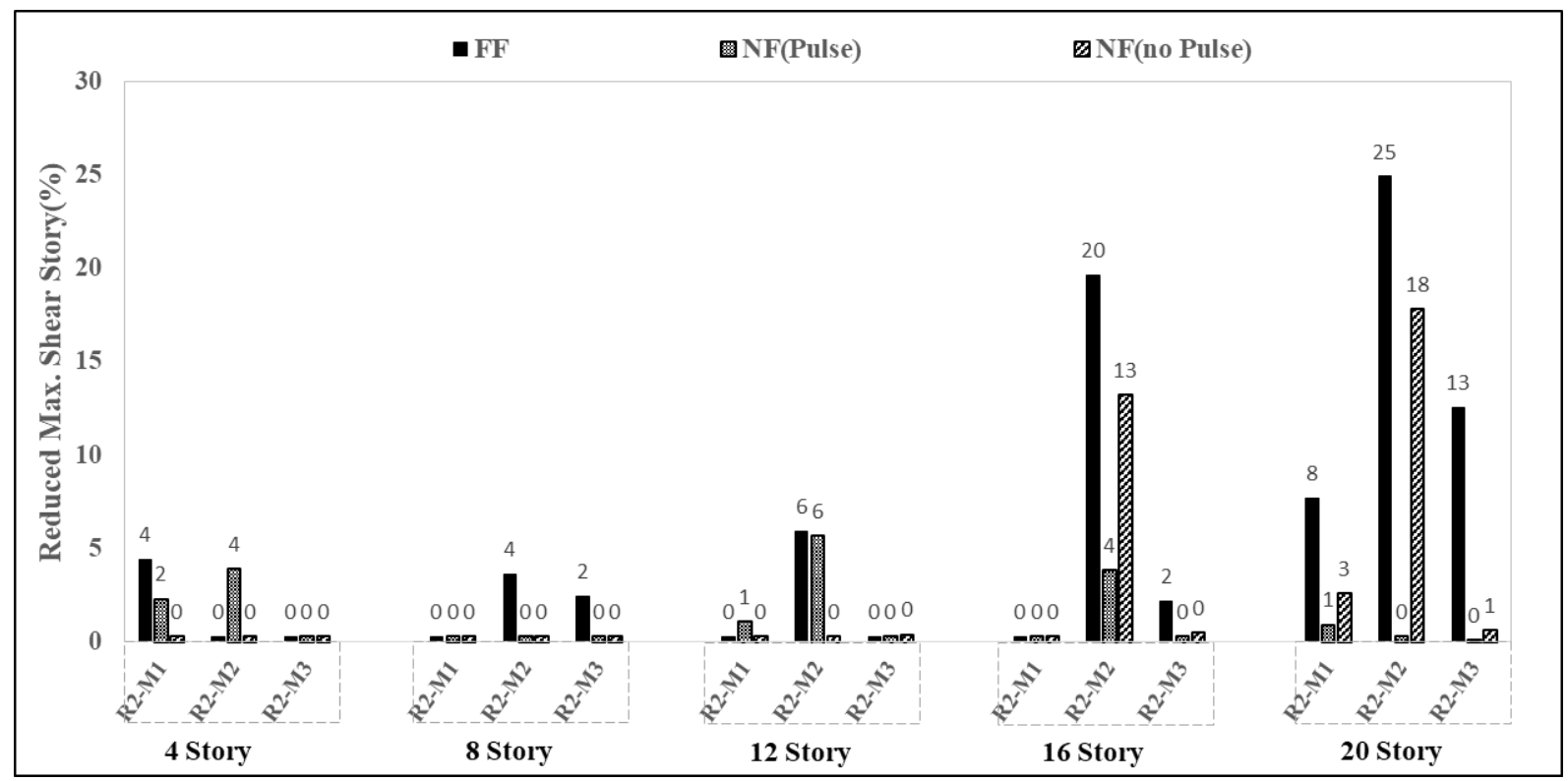

Figure 27. Percentage of the shear reduction in the bi-rocking walls compared to the simple walls under different seismic records

For each structure, the proposed bi-rocking walls under different seismic records are presented in Table 2. The employment of these walls can bring about a better performance for any type of structure under any seismic records. According to Table 2, doubling the wall at the height of one-fourth (M1) is more effective for walls located in NF (pulse). While, doubling the wall in 
one-fourth (M1) is more effective for walls located in FF and NF (no pulse) areas for low-rise structures with 4, 8 and 12 stories. It is also more effective in the one-half height (M2) of the wall for high-rise structures with 16 and 20 stories. For instance, for a 20-story building under FF and NF (pulse and no pulse) records, the rocking walls R2-M1, R2-M2, and R2-M2, are recommended, respectively. The R2-M2 wall in a 20-story building under the FF record reduces the moment and shear by $40.6 \%$ and $25 \%$, respectively. The R2-M1 wall in a 20 -story building under NF (pulse) records reduces the moment and shear by $22 \%$ and $1 \%$, respectively. The R2M2 wall in a 20-story building under NF (no pulse) records reduces the moment and shear by $41.1 \%$ and $18 \%$, respectively. For other buildings, the percentages of the moment and shear reduction can be examined in the same way.

Table 2. Proposed bi-rocking sections for the rocking structures

\begin{tabular}{cccc}
\hline Structure & FF & NF(Pulse) & NF(no Pulse) \\
\hline 04 Story & R2-M1 & R2-M1 & R2-M1 \\
08 Story & R2-M1 & R2-M1 & R2-M1 \\
12 Story & R2-M1 & R2-M1 & R2-M1 \\
16 Story & R2-M2 & R2-M1 & R2-M2 \\
20 Story & R2-M2 & R2-M1 & R2-M2 \\
\hline
\end{tabular}

To ensure that the cables of the rocking systems do not yield, the values of the stress ratio in the cables of the rocking systems were examined. As shown in Figure 28, the stress ratio values in all PT cables are less than one; therefore, it can be concluded that none of the cables would yield under the intended records. The effect of NF (pulse) earthquakes is higher on cables and causes more stress in them (Figure 28). 


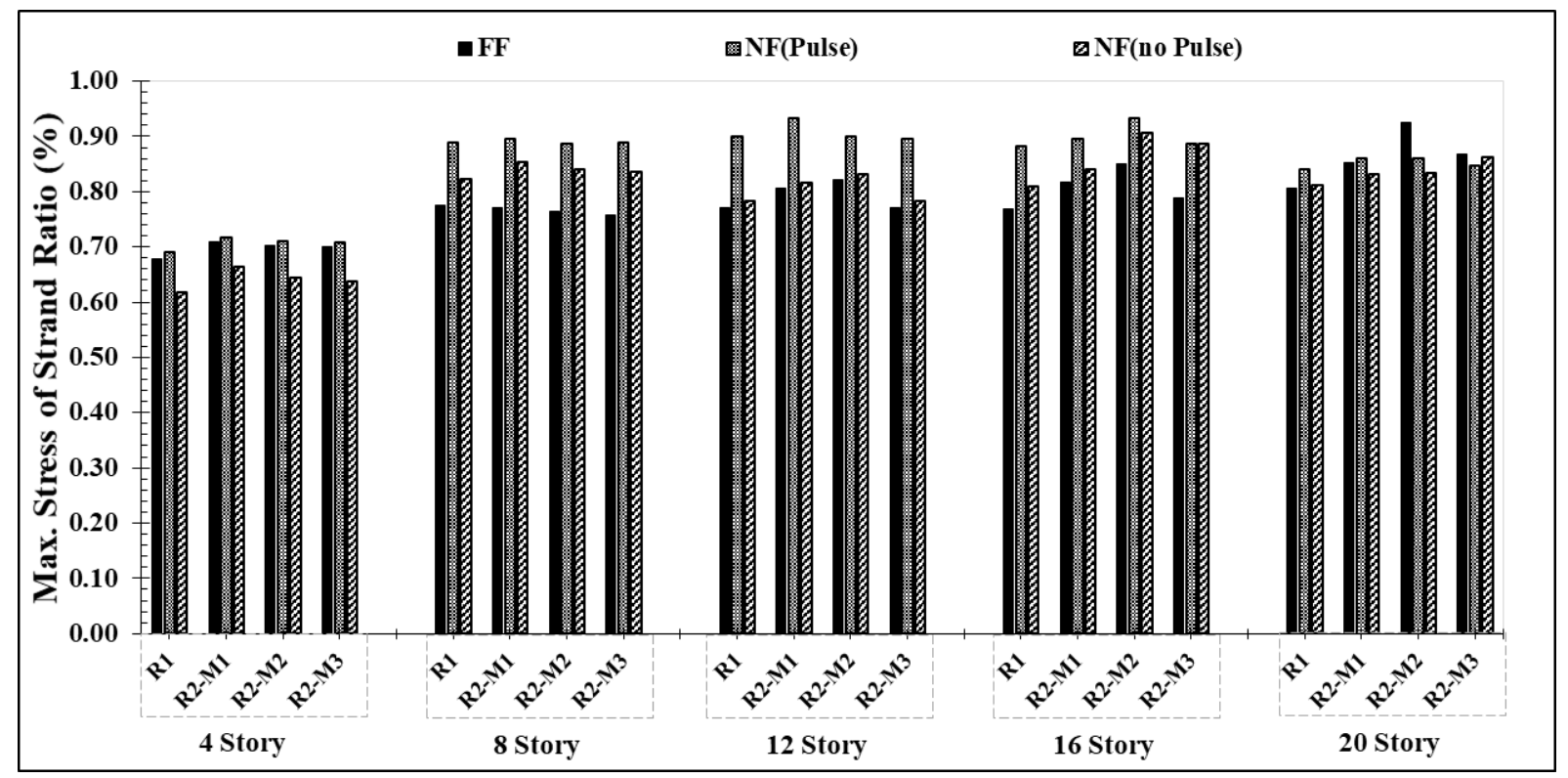

Figure 28. Stress ratio in PT cables under different seismic records

\section{Conclusions}

The current study investigated the behavior of base-rocking and bi-rocking walls under FF and NF (pulse and no pulse) earthquake records. The previously developed displacement-based design method was examined under different seismic records. The concept of adverse effects of higher modes on rocking structures was thoroughly addressed. Bi-rocking system as a mean to reduce the higher-mode effects was elaborated. The optimal placement of the second joint section in bi-rocking walls was obtained using different earthquake records. To determine the best location of the rocking section, three height levels of one-fourth (R2-M1), half (R2-M2), and three-fourths (R2-M3) were investigated. The obtained results are outlined below: The phenomenon of higher modes in base-rocking systems causes excessive moment and shear demands on the core resulting in damages to the rocking core. Therefore, appropriate measures need to be taken so as to reduce this effect.

- The design approach based on the direct displacement method showed a reasonable performance in 4, 8, and 12-story self-centering rocking structures under FF and NF (no pulse) earthquake records. It provided desirable results in terms of the maximum inter-story drifts. However, the aforementioned design method might not be appropriate for structures under NF (pulse) records since the drifts of all the considered structures, exceeded the design limit. 
- The moment and shear demands resulted from the effects of higher modes on the rocking walls were intensified by the increase in height.

- The inter-story drifts under the NF (pulse) records were dramatically greater than those under the FF and NF (pulse) records. Furthermore, in most cases the drifts of the bi-rocking wall systems were greater than those in the base-rocking systems.

- Residual drifts of rocking and bi-rocking structures could be ignored. Moreover, by comparing the residual drifts of stories, it is concluded that by an increase in story level, the value of residual drift augments accordingly. In most cases, the residual drifts of FF records were higher than those of NF records.

- As the height of structure increases, changing a base-rocking wall to a bi-rocking one would be more effective in reducing the higher-mode effects (in terms of moment and shear demands on rocking core). In this respect, the tallest structure considered in this research project (20-story structure) experienced a reduction of $41 \%$ and $25 \%$ in moment and shear demands, respectively.

- The most efficient bi-rocking wall system among 4, 8, and 12-story structures under all the considered seismic records was R2-M1 wall type. However, for 16 and 20-story structures, R2-M2 was the best choice under FF and NF-no pulse records and R2-M1 was the best option under NF-with pulse.

- The stresses created in the cables of rocking and bi-rocking systems had a ratio of less than 1. The stresses of rocking and bi-rocking systems were almost the same. In most of the structures, stresses caused by NF-pulse records had greater values compared to those of FF and NF-no pulse records with the maximum difference of about $13 \%$.

Given the merits of bi-rocking systems, they may be employed as alternative systems to conventional and base-rocking structures. In this regard, the following subjects are suggested as future research:

- Since the fragility curves in self-centering multiple rocking walls would be effective for engineering judgment, developing fragility curves for these walls is suggested.

- To investigate the effects of higher modes in rocking systems, new methods such as adaptive pushover analysis may be used. 
- For mid-rise and high-rise buildings, the combination of self-centering multiple rocking walls and other structural systems such as moment resisting frames or bracing frames is suggested.

\section{Declarations}

- Availability of data and material: The data that support the findings of this study are available on request from the corresponding author.

- Competing interests. The authors declare that they have no competing interests.

- Funding: This study is financially supported by the Iranian National Science Foundation (INSF) for its financial support.

- Acknowledgements: Not applicable.

\section{References}

Aragaw, Leikune F. and Paolo M. Calvi. 2020. "Comparing the Performance of Traditional Shear-Wall and Rocking Shear-Wall Structures Designed Using the Direct-Displacement Based Design Approach.” Bulletin of Earthquake Engineering 18(4):1345-69.

Archila, Manuel. 2014. "Directionality Effects of Pulse-like near Field Ground Motions on Seismic Response of Tall Buildings."

ASCE/SEI 7. 2016. "Minimum Design Loads for Buildings and Other Structures (ASCE/SEI 7-16)." American Society of Civil Engineers.

Brunesi, E., S. Peloso, R. Pinho, and R. Nascimbene. 2018. "Cyclic Testing of a Full-Scale Two-Storey Reinforced Precast Concrete Wall-Slab-Wall Structure.” Bulletin of Earthquake Engineering 16(11):5309-39.

Chancellor, Nathan, Matthew Eatherton, David Roke, and Tuğçe Akbaş. 2014. "Self-Centering Seismic Lateral Force Resisting Systems: High Performance Structures for the City of Tomorrow." Buildings 4(3):520-48.

Eatherton, Matthew R., Xiang Ma, Helmut Krawinkler, David Mar, Sarah Billington, Jerome F. Hajjar, and Gregory G. Deierlein. 2014. "Design Concepts for Controlled Rocking of Self-Centering SteelBraced Frames.” Journal of Structural Engineering 140(11):4014082.

FEMA-P695. 2009. FEMA P695 :Quantification of Building Seismic Performance Factors. US Department of Homeland Security, FEMA.

Grigorian, Mark. 2021. "Resiliency and Post-earthquake Realignment." The Structural Design of Tall and Special Buildings 30(5):e1836.

Grigorian, Mark and Mozhgan Kamizi. 2019. "On the Analysis of Multilevel Rocking Cores-A Bioinspired Analogy.” Engineering Reports 1(1):e12025.

Grigorian, Mark, Abdolreza S. Moghadam, Hadiseh Mohammadi, and Mozhgan Kamizi. 2019. "Methodology for Developing Earthquake-resilient Structures." The Structural Design of Tall and Special Buildings 28(2):e1571.

Gu, Anqi, Ying Zhou, Yi Xiao, Qingwu Li, and Ge Qu. 2019. “Experimental Study and Parameter Analysis on the Seismic Performance of Self-Centering Hybrid Reinforced Concrete Shear Walls." 
Soil Dynamics and Earthquake Engineering 116:409-20.

Guo, Guiqiang, Leibo Qin, Dixiong Yang, and Yunhe Liu. 2020. "Dimensional Response Analysis of Rocking Wall-Frame Building Structures with Control Devices Subjected to near-Fault Pulse-like Ground Motions.” Engineering Structures 220:110842.

Hasan, M. R. 2012. "Parametric Study and Higher Mode Response Quantification of Steel Self-Centering Concentrically-Braced Frames." University of Akron.

Holden, Tony, Jose Restrepo, and John B. Mander. 2003. "Seismic Performance of Precast Reinforced and Prestressed Concrete Walls.” Journal of Structural Engineering 129(3):286-96.

Kang, Su-Min, Ook-Jong Kim, and Hong-Gun Park. 2013. "Cyclic Loading Test for Emulative Precast Concrete Walls with Partially Reduced Rebar Section.” Engineering Structures 56:1645-57.

Khanmohammadi, Mohammad and Sajad Heydari. 2015. "Seismic Behavior Improvement of Reinforced Concrete Shear Wall Buildings Using Multiple Rocking Systems.” Engineering Structures 100:57789.

Kurama, Yahya C. 2000. "Seismic Design of Unbonded Post-Tensioned Precast Concrete Walls with Supplemental Viscous Damping.” ACI Structural Journal 97(4):648-58.

Kurama, Yahya C. 2001. "Simplified Seismic Design Approach for Friction-Damped Unbonded PostTensioned Precast Concrete Walls.” ACI Structural Journal 98(5):705-16.

Kurama, Yahya C. 2002. "Hybrid Post-Tensioned Precast Concrete Walls for Use in Seismic Regions." PCI Journal 47(5):36-59.

Kurama, Yahya, D. Ph, Stephen Pessiki, and D. Ph. 1999. "Seismic Behavior and Design of Unbonded Post-Tensioned Precast Concrete Walls.” PCI Journal (May-June):18.

Li, Tao, Jeffrey W. Berman, and Richard Wiebe. 2017. "Parametric Study of Seismic Performance of Structures with Multiple Rocking Joints.” Engineering Structures 146:75-92.

Li, Xiangmin, Fuwen Zhang, Kun Tian, Zhuolin Wang, Lu Jiang, and Jinzhi Dong. 2021. "Shaking Table Test for Externally-Hung Self-Centering Rocking Wall Structure.” Bulletin of Earthquake Engineering 19(2):863-87.

Martin, Amory and Gregory G. Deierlein. 2021. "Generalized Modified Modal Superposition Procedure for Seismic Design of Rocking and Pivoting Steel Spine Systems.” Journal of Constructional Steel Research 183:106745.

Masrom, Mohd Asha' ari and Nor Hayati Abdul Hamid. 2020. "Review on the Rocking Wall Systems as a Self-Centering Mechanism and Its Interaction with Floor Diaphragm in Precast Concrete Structures." Latin American Journal of Solids and Structures 17(6).

Mpampatsikos, Vassilis, Michele Egidio Bressanelli, Andrea Belleri, and Roberto Nascimbene. 2020. “A Non-Dimensional Parametric Approach for the Design of PT Tendons and Mild Steel Dissipaters in Precast Rocking Walls.” Engineering Structures 212:110513.

Nazari, Maryam and Sri Sritharan. 2020. "Influence of Different Damping Components on Dynamic Response of Concrete Rocking Walls.” Engineering Structures 212:110468.

Pennucci, D., G. M. Calvi, and T. J. Sullivan. 2009. "Displacement-based Design of Precast Walls with Additional Dampers." Journal of Earthquake Engineering 13(S1):40-65.

Perez, Felipe De Jesus. 1998. "Lateral Load Behavior and Design of Unbonded Post- Tensioned Precast 
Concrete Walls with Ductile Vertical Joint Connectors Lateral Load Behavior and Design of Unbonded Post- Tensioned Precast Concrete Walls with Ductile Vertical Joint Connectors."

Perez, Felipe J., Stephen Pessiki, and Richard Sause. 2004. "Seismic Design of Unbonded Concrete Walls with Vertical Joint Connectors.” PCI Journal 49(1):58-79.

Perez, Felipe J., Stephen Pessiki, and Richard Sause. 2013. "Experimental Lateral Load Response of Unbonded Post-Tensioned Precast Concrete Walls.” ACI Structural Journal 110(6).

Rahgozar, Navid and Nima Rahgozar. 2020. "Extension of Direct Displacement-based Design for Quantifying Higher Mode Effects on Controlled Rocking Steel Cores.” The Structural Design of Tall and Special Buildings 29(16):e1800.

Rahgozar, Navid and Nima Rahgozar. 2021. "Proposal of Lateral Forces for Capacity Design of Controlled Rocking Steel Cores Considering Higher Mode Effects.” Pp. 1086-96 in Structures. Vol. 30. Elsevier.

Rahgozar, Nima, Abdolreza S. Moghadam, and Armin Aziminejad. 2018. "Cantilever Beam Analogy for Modal Analysis of Rocking Core-Moment Frames." Bulletin of Earthquake Engineering 16(9):4081-4106.

Restrepo, José I. and Amar Rahman. 2007. "Seismic Performance of Self-Centering Structural Walls Incorporating Energy Dissipators.” Journal of Structural Engineering 133(11):1560-70.

Shoujun, Wu, Pan Peng, and Zhang Dongbin. 2016. "Higher Mode Effects in Frame Pin-supported Wall Structure by Using a Distributed Parameter Model.” Earthquake Engineering \& Structural Dynamics 45(14):2371-87.

Sun, Tianshu, Yahya C. Kurama, and Jinping Ou. 2018. "Practical Displacement-Based Seismic Design Approach for PWF Structures with Supplemental Yielding Dissipators." Engineering Structures 172:538-53.

Tong, Fei and Constantin Christopoulos. 2020. "Uncoupled Rocking and Shear Base-mechanisms for Resilient Reinforced Concrete High-rise Buildings.” Earthquake Engineering \& Structural Dynamics.

Wada, Akira, Zhe Qu, Shojiro Motoyui, and Hiroyasu Sakata. 2011. "Seismic Retrofit of Existing SRC Frames Using Rocking Walls and Steel Dampers." Frontiers of Architecture and Civil Engineering in China 5(3):259.

Wiebe, L. and C. Christopoulos. 2009. "Mitigation of Higher Mode Effects in Base-Rocking Systems by Using Multiple Rocking Sections.” Journal of Earthquake Engineering 13(1 SUPPL. 1):83-108.

Wiebe, L, C. Christopoulos, R. Tremblay, and M. Leclerc. 2013a. "Mechanisms to Limit Higher Mode Effects in a Controlled Rocking Steel Frame. 1: Concept, Modelling, and Low-Amplitude Shake Table Testing." Earthquake Engineering and Structural Dynamics 42(7):1053-68.

Wiebe, Lydell and Constantin Christopoulos. 2015. "A Cantilever Beam Analogy for Quantifying Higher Mode Effects in Multistorey Buildings.” Earthquake Engineering \& Structural Dynamics 44(11):1697-1716.

Wiebe, Lydell, Constantin Christopoulos, Robert Tremblay, and Martin Leclerc. 2013b. "Mechanisms to Limit Higher Mode Effects in a Controlled Rocking Steel Frame. 2: Large-amplitude Shake Table Testing." Earthquake Engineering \& Structural Dynamics 42(7):1069-86.

Wiebe, Lydell Deighton Andree. 2013. "Design of Controlled Rocking Steel Frames to Limit Higher 
Mode Effects."

Wu, Dayang, Bin Zhao, and Xilin Lu. 2018. "Dynamic Behavior of Upgraded Rocking Wall-Moment Frames Using an Extended Coupled-Two-Beam Model." Soil Dynamics and Earthquake Engineering 115(January):365-77. 